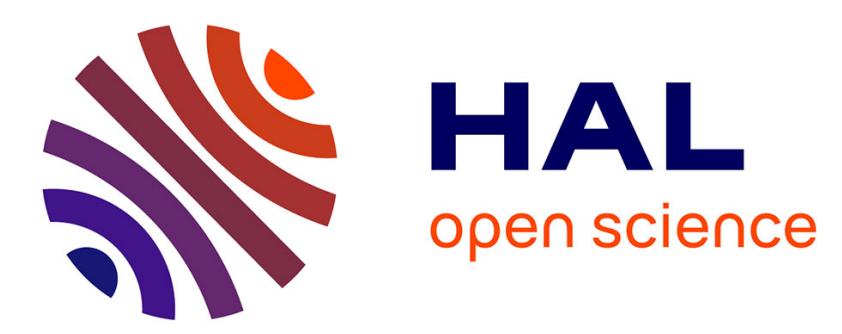

\title{
Pore-Level Investigation of Heavy Oil Recovery using Steam Assisted Gravity Drainage (SAGD)
}

\author{
O. Mohammadzadeh, I. Chatzis
}

\section{To cite this version:}

O. Mohammadzadeh, I. Chatzis. Pore-Level Investigation of Heavy Oil Recovery using Steam Assisted Gravity Drainage (SAGD). Oil \& Gas Science and Technology - Revue d'IFP Energies nouvelles, 2010, 65 (6), pp.839-857. 10.2516/ogst/2010010 . hal-01937582

\section{HAL Id: hal-01937582 \\ https://hal.science/hal-01937582}

Submitted on 28 Nov 2018

HAL is a multi-disciplinary open access archive for the deposit and dissemination of scientific research documents, whether they are published or not. The documents may come from teaching and research institutions in France or abroad, or from public or private research centers.
L'archive ouverte pluridisciplinaire HAL, est destinée au dépôt et à la diffusion de documents scientifiques de niveau recherche, publiés ou non, émanant des établissements d'enseignement et de recherche français ou étrangers, des laboratoires publics ou privés. 


\title{
Pore-Level Investigation of Heavy Oil Recovery using Steam Assisted Gravity Drainage (SAGD)
}

\author{
O. Mohammadzadeh and I. Chatzis \\ Department of Chemical Engineering, University of Waterloo, Waterloo, Ontario N2L 3G1 - Canada \\ e-mail: omohamma@uwaterloo.ca - ichatzis@uwaterloo.ca
}

\begin{abstract}
Résumé - Étude à l'échelle des pores de la récupération d'huiles lourdes par drainage gravitaire assisté par injection de vapeur (SAGD) - L'application réussie du procédé de drainage gravitaire assisté par injection de vapeur à l'aide de puits horizontaux lors de divers essais de champ, essentiellement au Canada, montre qu'on peut atteindre un taux de récupération élevé et des rapports vapeur injectée/pétrole récupéré économiquement viables. Le procédé de récupération par SAGD a été développé sur le plan théorique, testé sur pilote et commercialisé, tout cela au Canada; il reste cependant encore plusieurs problèmes techniques à résoudre dans ce procédé. Les phénomènes qui se développent à l'échelle des pores lors de la récupération d'huiles lourdes à l'aide du procédé SAGD ne sont pas encore très bien compris, ce qui conduit à intégrer la physique du processus au niveau des pores dans des modèles mathématiques. L'étude à l'échelle des pores des phénomènes physiques concernant la distribution des fluides et les types d'écoulement dans le milieu poreux dans ce procédé devrait apporter une nette amélioration de la compréhension des phénomènes macroscopiques observés aussi bien en laboratoire que sur le terrain. L'objectif principal de cet article est l'étude visuelle et la description des phénomènes à l'échelle des pores par l'utilisation d'un micromodèle en verre. Des expériences de SAGD ont été effectuées au laboratoire sur des micromodèles de réseaux capillaires gravés sur des plaques de verre qui, au départ, ont été saturés d'huile lourde. Ces expériences furent réalisées dans une chambre à vide pour éviter des pertes de chaleur excessives vers l'extérieur. Les premiers résultats montrent que lorsque l'interface huile lourde/vapeur est établie, un processus de drainage gravitaire a lieu dans une couche de pores, d'une épaisseur de 1 à 6 pores, suivant une direction perpendiculaire à cette interface. L'interaction entre les forces gravitaires et les forces capillaires se traduit par un drainage de l'huile mobilisée. Les résultats de la visualisation démontrent l'existence d'un phénomène de mise en émulsion de l'eau dans l'huile au niveau de l'interface, dû à la condensation de la vapeur. L'importance de cette mise en émulsion dépend directement du gradient de température entre la phase vapeur et le bitume froid. L'utilisation de micromodèles en verre permet aussi la visualisation d'autres phénomènes à l'échelle des pores, comme le drainage par écoulement capillaire de l'huile mobilisée, le piégeage local de la vapeur par effet capillaire suivi d'une condensation, la condensation de la vapeur à l'interface due au gradient de température et la rupture des films liquides.
\end{abstract}

\footnotetext{
Abstract - Pore-level Investigation of Heavy Oil Recovery using Steam Assisted Gravity Drainage (SAGD) - Successful application of gravity drainage process, facilitated with steam injection, using horizontal wells in various field tests, especially within Canada, indicates that high recovery factor and also economical steam to oil ratios are achievable. Steam Assisted Gravity Drainage recovery scheme was theoretically developed, pilot tested, and commercialized in Canada; however, there are still several technical challenges to be solved in this process. The pore-scale events of heavy oil recovery in SAGD process are not yet well understood to the extent of incorporating pore-level physics of the process into
} 
mathematical models. Investigation of the physics of fluid distribution and flow behavior in porous media for SAGD process at the pore-scale is expected to result in significant improvement in understanding the macroscopic phenomena observed in either laboratory or field scale. The main objective of this paper is to visually investigate and to document the pore-scale events of the SAGD process using glass micromodel type of porous media. SAGD experiments were carried out in micromodels of capillary networks etched on glass plates which were initially saturated with heavy oil. Experiments were conducted in a vacuum chamber in order to reduce the excessive heat loss to the surrounding environment. Initial results indicate that when the heavy oil-steam interface is established, gravity drainage process takes place through a layer of pores, with a thickness of 1-6 pores, in the direction perpendicular to the interface. The interplay between gravity and capillarity forces results in the drainage of mobilized oil. The visualization results demonstrate the phenomenon of water in oil emulsification at the interface due to the local steam condensation. The extent of emulsification depends directly to the temperature gradient between the steam phase and cold bitumen. Other pore-scale phenomena such as film-flow drainage type of mobilized oil, localized entrapment of steam due to the capillarity followed by condensation, steam condensation at the interface due to temperature gradient, and snap-off of liquid films are also illustrated using glass micromodels in pore-level visualization experiments.

\section{INTRODUCTION}

Heavy oil and bitumen are of great economic importance to Canada. The quantity of oil in place in the form of bitumen in Canada is as great as that of the conventional crude oil in the Middle East and it is a major Canadian technical challenge to utilize this vast resource efficiently and economically. A recent estimate of the recoverable volume represents only $12 \%$ of the volume of bitumen in place, based on the available economic conditions. However, there is considerable potential for this percentage to increase as advances are made in the recovery technologies. Recently, the reserves are estimated to be 28.3 billion cubic meters, made up of only 5.6 billion cubic meters in the surface-mineable areas and 22.7 billion cubic meters for the deeper areas. This total volume is sufficient to satisfy total Canadian demand for crude oil, at current rates, for approximately 250 years [1]. Thermal recovery techniques have been proved to be effective methods of utilizing heavy oil, extra heavy oil, and bitumen considering their in-situ upgrading potential as well as economic considerations. Among the vast spectrum of thermal recovery techniques, Steam Assisted Gravity Drainage (SAGD) seems a suitable recovery candidate especially for the Canadian and Venezuelan unconventional viscous hydrocarbon resources because of their unique unconsolidated lithology and its associated high vertical permeability.

The original concept of Steam Assisted Gravity Drainage (SAGD) recovery technique has been proposed by Butler and his coworkers in late 1970's by taking advantage of the traditional steam flooding experiences and the newly developed horizontal well technology. The novel idea behind the SAGD method has been developed and modified by Roger Butler through subsequent years [2-9]. As it is schematically depicted in Figure 1, SAGD recovery technique involves drilling of two horizontal wells parallel to each other near the basal part of the pay zone with definite vertical spacing from each other. Steam is injected under constant injection pressure through the upper well (injector) while condensates and drained mobilized oil are produced from the lower production well. Oil movement towards the producer is caused by the resultant action of gravity and capillarity forces. Injected steam would form a continuously growing steam-saturated zone called "steam chamber" which is the nominal interface of hot steam phase and cold bitumen zone. Steam condenses at the perimeter of the steam chamber, hence giving the librated latent heat of condensation to the cold bitumen in order to reduce its viscosity. The mobilized oil as well as steam condensates move approximately parallel to the steam chamber interface towards the producer. Using this recovery technique, heavy oil or bitumen can be extracted in a systematic manner in order to give higher ultimate recovery values than that of the conventional steam-flooding process, in which oil is moved by pushing it with the injected fluids.

Using gravity force for oil production prevents possible differential fingering that occurs when viscous crude is pushed with a less viscous fluid (gas, steam, or water at corresponding flooding processes). As far as the overall evolution of this gravity dominated process is concerned, each particular SAGD pattern would be progressed through four successive typical stages which are depicted in Figure 2. These stages are classified based on the relative growth of the steam-saturated zone as follows:

- establishing an early communication between paired horizontal wells (Fig. 2b);

- vertical encroachment of the steam chamber (Fig. 2c,d);

- outward (i.e. lateral) spreading of the steam chamber (Fig. 2d,e), and; 


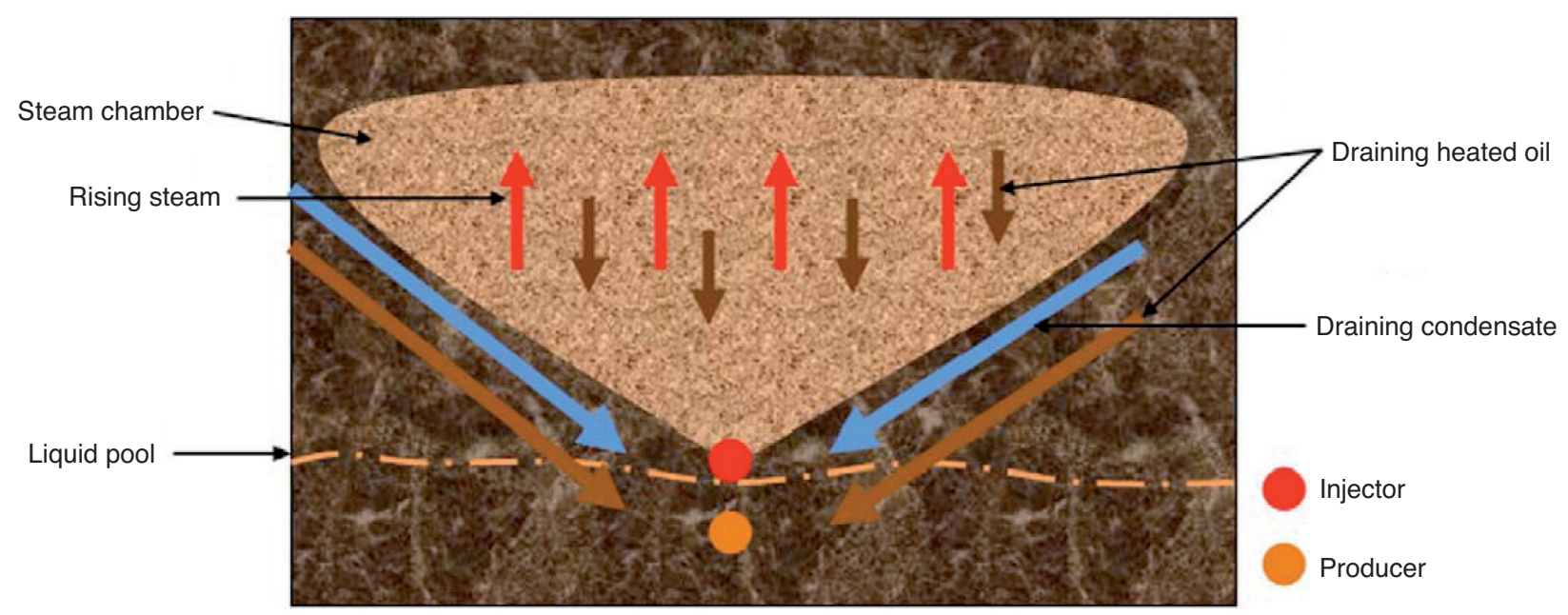

Figure 1

SAGD Conceptual Flow Diagram [10].

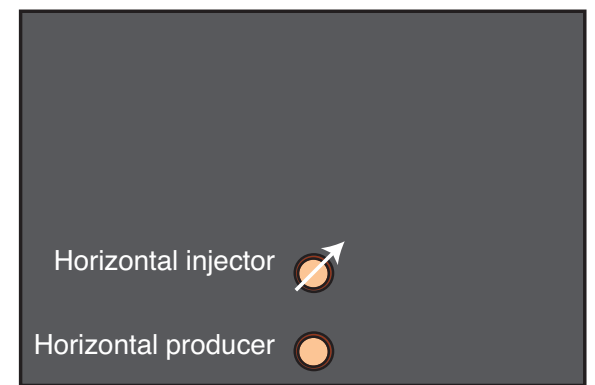

a)

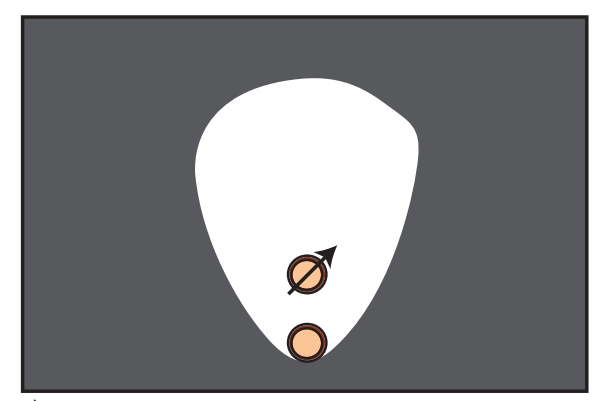

c)

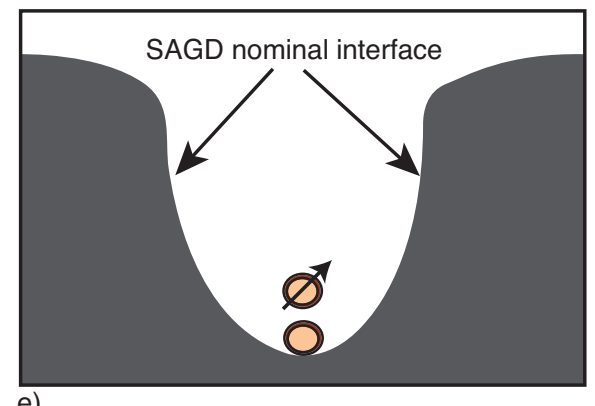

e)

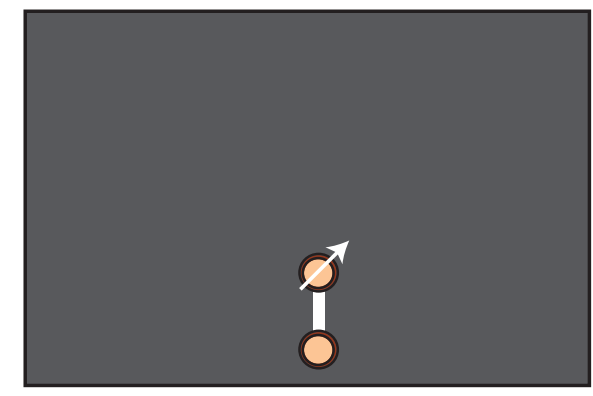

b)

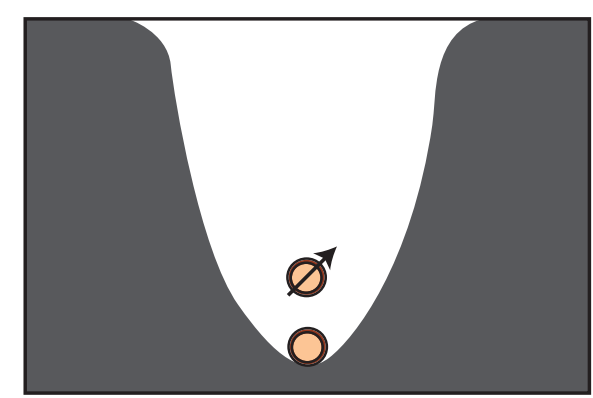

d)

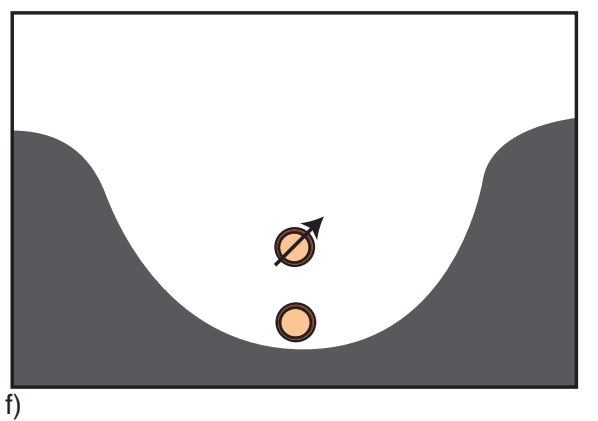

Figure 2

Different stages of SAGD swept pattern evolution. 
- falling-down phase of the steam chamber leading to the reservoir depletion (Fig. 2f).

Although the SAGD process looks simple and straightforward at the first glance, there are still several concerns regarding the concept itself, as well as pertaining theories and actual involving mechanisms. Aside from the extensive laboratory, simulation, pilot-scale, and field-scale attempts conducted to study the performance, technical aspects, economical issues, and feasibility of this recovery technique, there are still numerous challenges which have been remained unsolved. A vast series of these challenging topics have been pointed out in an excellent review paper, recently published by Al-Bahlani and Babadagli [10]. According to this article, a main challenging group of these concerns is related to the lack of understanding of the actual physics of the SAGD process. One can divide the inherent pitfalls of the SAGD process into two main groups of micro-scale (i.e. pore-level) and macro-scale issues.

It is evident that this lack of knowledge is present in both micro- and macro-scale fields of study to the extent at which the predicted SAGD process performance obtained from different resources (such as regular scaling up procedures of the experimental data, relevant analytical models, and numerical reservoir simulations) would not be verified by the attributed pilot tests and field trials. The focus of this paper is to mechanistically study the pore-scale aspects of the SAGD process by which some of the challenging micro-scale issues of this recovery method could be resolved. It is believed that with a detailed and precise review process and documentation of the events happening at the pore-level during the SAGD process, the associated micro-scale recovery mechanisms could be enlighten to the extent of incorporating these mechanistic findings into the mathematical models and numerical simulators. Visualization experiments using glass micromodel type of porous media were selected for this purpose, pore-scale events were recorded using digital photo capturing techniques, and the captured snap-shots were analyzed using image processing procedures. Details of the experimental design and methodologies are described later.

Micromodels are created to replicate porous media in order to visualize chemical and particulate transport processes at the pore level. Micromodels are generally small in size, with inlet and outlet hole(s) drilled into the flow system to facilitate injection and production of chemical substances, as well as to create and maintain a steady flowing system. One efficient form of micromodels that helps to quantify basic transport phenomena could be composed of simple porous networks of fixed-geometry of pore bodies connected by pore throats. The medium employed to create micromodels can be glass, silicon, or even polymers, and the pore network can be either etched or created from a monolayer of substrate. Micromodels are built out of transparent materials to be able to see-through, making it feasible to visually investigate the ongoing process based on the captured photos/movies using image processing techniques. Two dimensional glass micromodels have been used widely to demonstrate fluid flow through porous media for petroleum engineering applications. Glass micromodel preparation procedure, which is based on the photo-fabrication process, originally came from the printed-circuit technology used in electromagnetic and electrical circuits industry. Considering advances made, it is relatively easy to make 2-D pore network models of even heterogeneous pore size and interconnections within transparent media such as glass [1116]. Since the porous structure is only a few pores deep, and the surrounding solids walls are all made of glass in a glass micromodel, it is feasible to observe the fluids as they flow along the pore channels and interact with each other. Another benefit of employing such a transparent porous model is the possibility of studying how the geometry of the porous network would affect the fluid flow patterns and also the trapping of the fluids within the network of pores. Various pore patterns including rock-look-alike and geometric patterns can be designed and etched. The choice of pore network pattern is normally made based on the objective of the visualization study. If the objective of micromodel experiments is to generate quantitative data for mathematical modeling of a physical fluid flow process, geometric patterns are preferable as they have pores with definite shapes and sizes. It is not necessarily a general rule, as one could find a mass of qualitative approaches of pore-scale studies in literature, performed using glass micromodels with geometric porous structures. On the other hand, rock-look-alike pore patterns are normally derived from porous rock thin sections and as a result, could resemble the real morphology and porous structure. However, it is much more difficult to mathematically model the fluid flow patterns within this type of porous structure as the pore shape, size, connectivity, tortuosity, and other porescale dimensions do not have uniform trends and behaviour. As a result, qualitative approach of pore-scale studies could then be facilitated much easier, and at the same time with higher confidence degrees (because of being representative of actual rock porous patterns), using this particular type of glass micromodels [14-16].

\section{MICRO-SCALE CHALLENGES OF THE SAGD PROCESS: LITERATURE REVIEW}

According to the mass of articles found in the literature, the experimental aspects related to the utilization of steam heating to produce heavy oil under gravity drainage process are limited to those which are conducted using scaled physical models. These results were used to acquire better understanding of the overall physics of the process, as well as help to predict intended field-scale performances based on the empirical scaling-up procedures. It is believed that the macro-scale production enhancement of a typical SAGD process depends significantly on the pore-level drainage mechanisms, so it is vital to capture the actual physics of this 
recovery process at the pore-level using relevant mechanistic studies. A series of pore-scale events and mechanisms are believed to have major contribution in the macro-scale performance of the SAGD process such as local fluid mixing at the pore bodies, snap-off mechanism of invading fluids, local conduction-convection heat transfer, pore-scale immiscible displacement of mobilized heavy oil with injected steam as well as steam condensate, local dilution effect as a result of pore-scale mass transfer and dispersivity (in case if a solvent would be co-injected along with the steam in the Solvent Assisted SAGD (SA-SAGD) processes), and microscale liquid-liquid emulsion evolution and its flow through the drainage path. As a result, it would be beneficial to critically analyze and document the pore-level phenomena of this process in order to obtain the relative contribution of each of these pore-scale events in the overall drainage scheme. As it was discussed earlier, numerous experimental attempts have been conducted so far to elucidate drainage mechanisms of the SAGD process. However, there are still some vague aspects, especially at the micro-scale of the process. In this section, some of these issues are discussed briefly.

\subsection{Steam Chamber Development}

As the drainage performance of a typical SAGD process is a strong function of the steam chamber occurrence and its evolution following the start-up stage, this stage has received a great deal of attention in scientific texts; however, there are still some complexities regarding the development stage of the steam-saturated zone [10]. For example, it was believed that the steam chamber is extended all the way down to the producer [4], and it was a challenge regarding controlling the process to the extent of avoiding steam breakthrough from the producer. However, recent studies of the steam chamber evolution highlighted that there is a pool of liquid phase above the producer, avoiding steam channeling and breakthrough from the producer $[17,18]$. Complexities of this form exist about different stages of steam chamber evolution which were schematically shown in Figure 2, such as probable cocurrent and counter-current local flow of different draining and invading phases, local heat transfer mechanism within the steam chamber and at its proximity, creation of local water-in-oil emulsion at the pore-level and its pertaining mechanisms, steam condensation phenomena near the nominal SAGD interface, drainage mechanisms of mobilized liquid phases leading to both lateral and vertical encroachment of the steam chamber, and fingering rise of the steam phase, to name a few. These phenomena have strong ties with the steam chamber evolution, and are discussed later.

\subsection{Steam Fingering Phenomenon}

The original theory of steam chamber vertical rise was hypothesized by Butler [5, 19] considering velocity equilibrium conditions between invading and draining phases through an arbitrary control volume within the steam chamber (Fig. 3a). Flat-front vertical encroachment style of

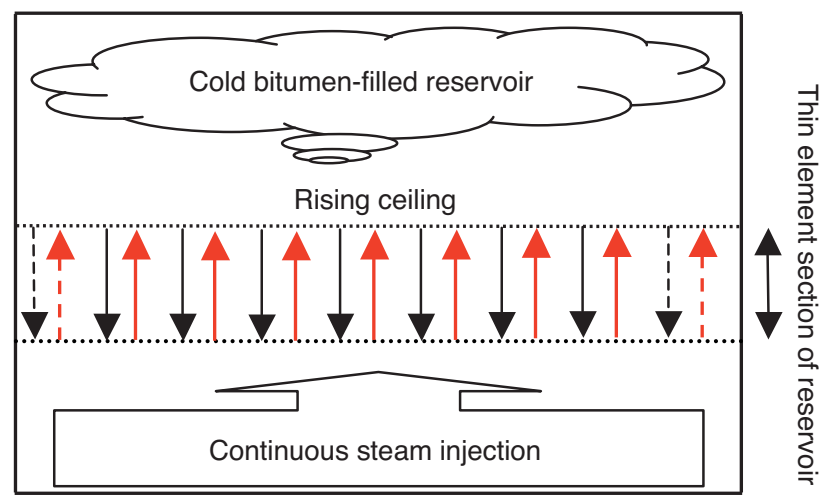

Planar injector

a)

Figure 3

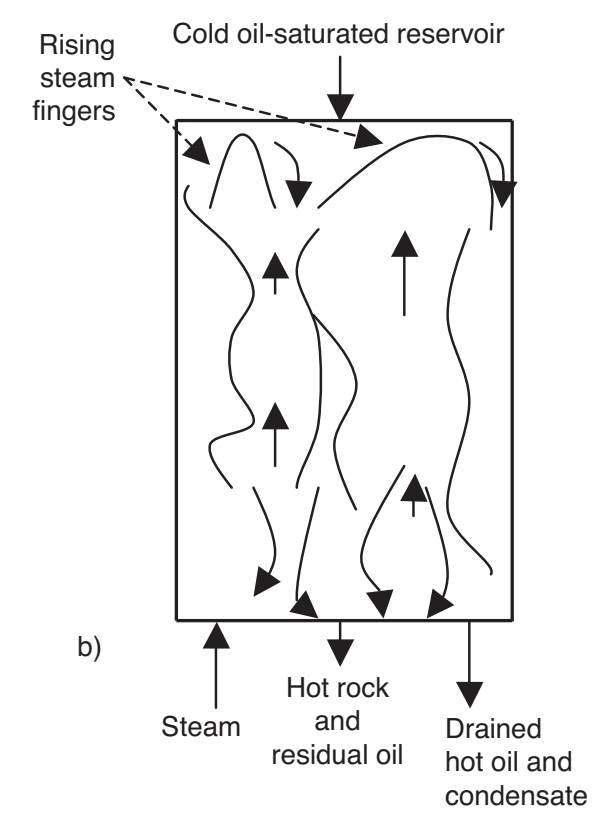

a) Linear countercurrent flow of rising steam and falling oil and condensate (modified from [5]), and b) hypothetical diagram of rising steam fingers (modified from [19]). 
the steam chamber was discredited both by scaled experimental results $[4,6]$ as well as numerical simulation of actual field trials [20-22]. It is believed that steam fingering phenomenon during the vertical encroachment of the steam chamber happens as a result of buoyancy advantage of steam to oil [10]. Although steam chamber is stable at its bottom part which is attached to the injector considering continuous nature of steam injection, buoyant steam phase near the top of the steam chamber has an inherently unstable interface with the thick, cold, and stagnant continuum of oil on the top. Figure $3 \mathrm{~b}$ shows the hypothetical approach of steam fingering at the elemental scale near the topside of the steam chamber. It is likely that the top side of the chamber would be dome-shaped, protruding from its upper surfaces, having a lot of steam fingers in it extending towards the reservoir ceiling. According to the literature, there is still doubt about the possibility of steam fingering in the outward direction, i.e. spreading phase of the steam chamber [10]. In the next sections, it is described that the conducted experiments facilitated means to visually examine the possibility and extent of steam channeling and fingering through the mobilized region ahead of the nominal SAGD interface.

\subsection{Fluid Flow Regimes and Drainage Mechanisms}

An overall SAGD pattern could be divided into different flow zones through which interacting fluid phases are flowing under the action of a combination of gravity, buoyancy, and capillarity forces in the absence of excessive viscous force. One could categorize these flow zones as:

- flow zone near the nominal SAGD interface along the side wings of the steam chamber;

- flow zone suited within the steam saturated zone far from the SAGD nominal interfaces, and;

- flow zone in the proximity of apparent SAGD interface towards the topside of the steam chamber.

The common terminologies used for SAGD front advancement, namely as co-current and counter-current steam front propagation, have been repeatedly used in scientific texts dealing with this recovery technique $[4,5,19,24,25]$. It is believed that one of the most complex fluid flow regimes of a typical SAGD process could be seen near the nominal interface along the lateral extensions of the steam chamber. In this particular position, both thermally-mobilized oil and steam condensate phases drain gravitationally along the lateral extension of the steam chamber towards the producer. This drainage is facilitated with the influence of a resultant driving force associated with both capillarity and gravity forces acting to the body masses of the draining liquids. Mobilized oil is unlikely to drain towards the interior's boundaries of the steam chamber. This was justified by the presence of steam condensate between steam and mobilized oil phases, and the tendency of the condensate to spontaneously imbibe through the pores already occupied by the mobilized oil in the presence of steam phase rather than draining back on top of the invading steam phase in the form of water films. On the other hand, steam phase is rising upwards inside the steam chamber at the proximity of its lateral extension. One could argue that a counter-current front propagation is responsible for the lateral expansion of the steam chamber. However, pore-scale results of our visualization experiments revealed that a much more complex fluid-flow pattern exists near the nominal SAGD interface, at the proximity of the lateral extension of the steam chamber, which will be discussed later.

As far as the fluid flow through the pore volume within the steam chamber itself is concerned, steam is the main flowing phase ascending vertically towards the pattern's topside constraint. As the residual oil saturation within the chamber itself is nil, oil relative permeability within the steam chamber could not reach the threshold value required for even creation of mobile oil films in the steam saturated zone $[4,5,23]$. In the case of probable steam condensation within the steam chamber, the evolved condensate could either drain counter-currently with respect to steam under the resultant force attributed to gravity (draining water phase) and buoyancy (rising steam phase) forces, or move laterally towards the lateral interfaces of the steam chamber through water-filled pores and then drain parallel to the SAGD apparent interface. As a result, it seems unlikely that much of the mobilized oil drains directly through the steam chamber and, even if it does, it finally drains into the interface located down gradient and re-joins the main draining oil stream [4,5]. Likewise the fluid flow regime at the proximity of the lateral extension of the steam chamber boundaries, our pore-scale results obtained from the conducted visualization experiments revealed more insight into the fluid flow pattern within the steam saturated zone which is discussed later.

Lastly, one would expect a counter-current steam front encroachment near the topside of the steam chamber at the proximity of the nominal SAGD interface due to the rising state of the steam phase (under the steam fingering scheme of flow) and draining nature of the mobilized oil as well as the steam condensate along the apparent interface. Due to specific design of our visualization experiments, it was not possible to look precisely into this particular fluid flow pattern. Overall, it seems that the steam interface advancement is due to a combination of both co-current and counter-current flow patterns [10]. It is noteworthy that the pore-scale mechanisms responsible for the drainage of mobilized oil, based on our visualization experiments, are discussed later in this article.

\subsection{Emulsification Phenomenon}

The topic of "emulsification phenomenon" during the typical SAGD process was covered in the literature based on the experiments conducted using scaled physical models as well 
as field-scale data [24, 26-31]. According to the field-scale trials of the SAGD process, the produced liquid is in the emulsion state composed of mobilized oil and water (either stable or unstable depending on the physicochemical characteristics of the interacting liquids as well as process operating conditions). The overall SAGD process performance is a trade-off between an increase in the draining liquid viscosity as a result of $i n$-situ emulsification and a decrease in the produced liquid viscosity as a result of continuous steam heating. In other words, success of a conventional SAGD process in terms of mobilized oil production depends on the following simultaneous events:

- viscosity reduction of the produced liquids and in-situ stagnant bitumen as a result of incessant steam heating, and at the same time;

- increase in the dynamic viscosity of the in-situ $\mathrm{W} / \mathrm{O}$ emulsion as a result of emulsification process itself, as well as continuous increase in the water volume fraction (i.e. water content) of the developed emulsion. This viscosity increase continues until the created emulsion would be produced at the production side, or when the associated water content of the emulsion reaches to its equilibrium (final) value, whichever is sooner.

It is also believed that the mechanistic aspects of the emulsion creation at the pore-level depend directly on the spreading characteristics of the interacting fluids. Once the injected steam has been contacted with the cold bitumensaturated pores, it would likely condense as soon as the local temperature drops below the dew point temperature at that particular operating pressure. Very fine water droplets produced at the chamber interface due to the condensation would move likely into the oil face (which has already been mobilized as a result of direct steam heating) immediately after generation. This microscopic invasion of very fine water droplets (in the order of 0.005 to $0.01 \mathrm{~mm}$ in diameter) into the bitumen-filled region would likely create water-in-oil emulsions which should be drained under the resultant force of gravity-capillarity interaction [28]. This emulsification hypothesis on a plane interface is illustrated schematically in Figure 4a. As it is shown in this figure, the steam phase is in contact with a falling film of live oil (i.e. mobilized oil with reduced viscosity as a result of steam heating). Although it is theoretically expressed that the steam chamber temperature stabilizes after initial chamber development (considering the fact that steam would be provided continuously for the system), it is expected to have a temperature gradient at the nominal interface and nearby area where the mobilized oil would be drained towards the production side. The state of in-situ viscosity of the draining emulsion and also the possible hierarchical manner of viscosity gain or loss of the draining emulsion is not yet fully understood. The viscosity of falling oil film, containing small isolated droplets of water, could be decreased as it drains down gradient because it approaches towards the high-temperature injection spot. Another possible scenario is that the associated emulsion viscosity could be increased while it drains gravitationally as a result of an increase in the water content (due to further local emulsification phenomenon which could be a monotonous process in nature) of the draining emulsion. Suppose that steam phase condenses on the plane surface of

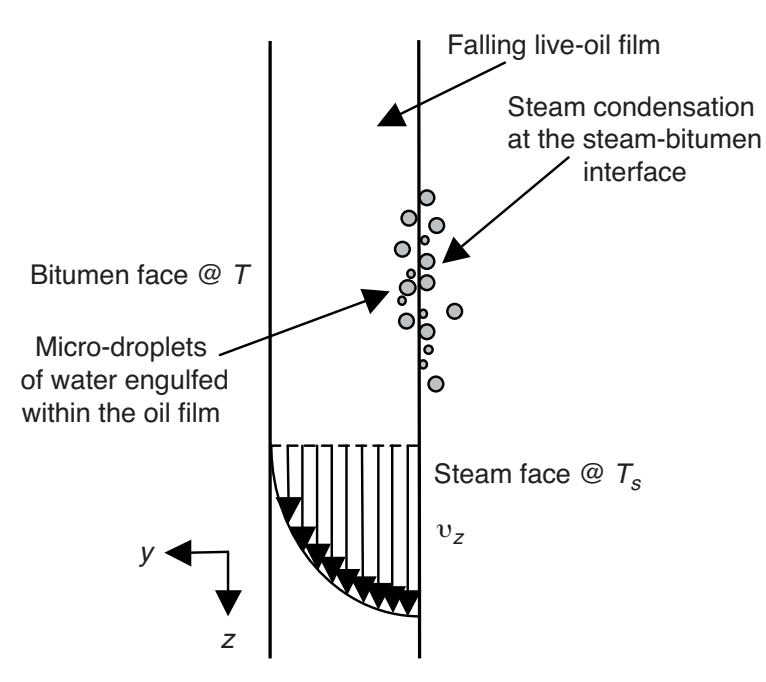

a)

Figure 4

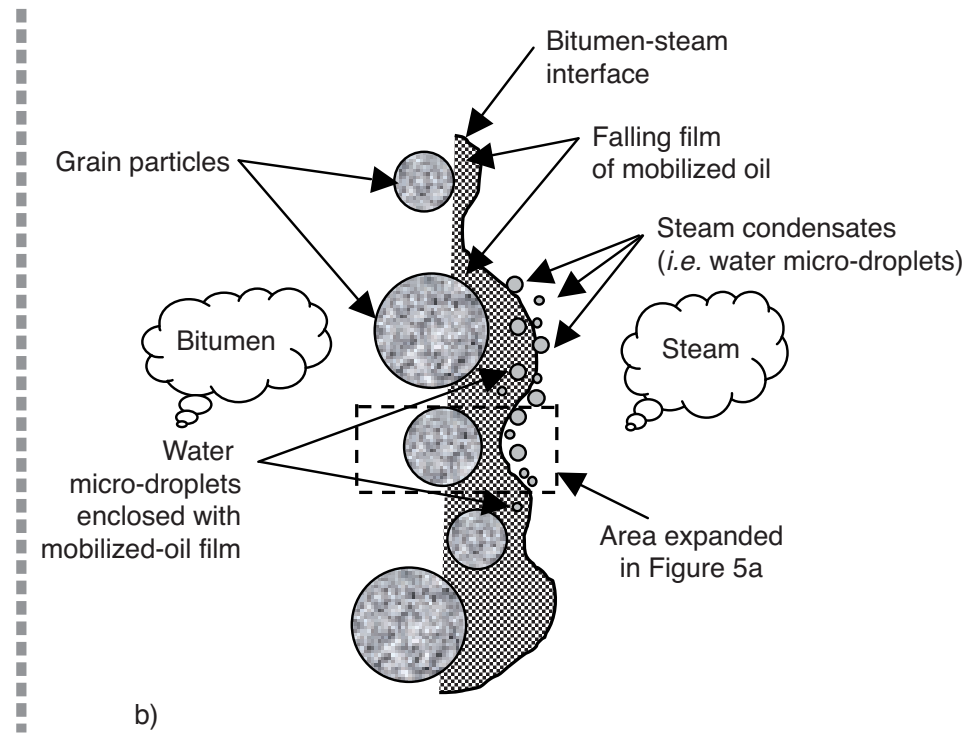

b)

Schematic hypothetical representation of steam condensation and water droplets engulfment processes in mobilized draining oil film at the a) planar steam-bitumen interface, and, b) porous media interface. 
falling live-oil film at $t=0$ as shown in Figure 4a. The resulting water droplets would be buried within the pool of oil continuum through an engulfing process, due to negative spreading coefficient of water on oil in the presence of a gas phase. These enclosed isolated water droplets would be drained downwards along with the falling oil film by the combined effect of drag force between water droplets and falling oil film, as well as the gravitational force. As time goes on, the cumulative amount of trapped water droplets (originated from the steam condensation process at the cold oil face) within the oil film tends to increase, while the draining film approaches towards the production end.

Another hypothetical view of the microscopic emulsion creation during the SAGD recovery scheme with focus on the nominal bitumen-steam interface and considering the pore structure events is presented in Figures $4 \mathrm{~b}$ and $5 \mathrm{a}$. As it is demonstrated in these figures, the falling film of mobilized oil forms an interface between the cold region (i.e. containing bitumen) and hot region (i.e. steam chamber). The grains could be either covered with water or oil depending on the initial saturation of the porous medium. As it is demonstrated in these figures, similar phenomena could happen at the porous media interface as that of the plane interface (Fig. 4a); the condensed water droplets are formed at the mobilized oil interface by the action of thermal gradient, they would be enclosed by the surrounding oil continuum, and then could be dragged towards the production side along with the falling film of mobilized oil. As steam condensation at the apparent SAGD interface proceeds, the latent heat of condensation transmitted to the colder oil face would mobilize it effectively. On the other hand, microscopic invasion of water micro-droplets through the mobilized oil boundaries would result in a gain in the apparent viscosity due to the local emulsion creation. According to our experimental results, it is evident that reduction of viscosity because of the thermal diffusion effect is much stronger than the share of viscosity increase as a result of local emulsification; otherwise, no mobilized oil flow stream would then be formed. The dotted rectangular area in Figure $4 \mathrm{~b}$ is expanded in Figure 5a to schematically show the details of $\mathrm{W} / \mathrm{O}$ emulsion creation at the pore level.

As it will be discussed further in the "Experimental results and discussion" section of this paper, the condensate (water) droplets encounter different flow patterns over their tortuous journey path towards the production spot. They could join together to form larger-sized trapped water droplets under specific circumstances, and still be drained gravitationally. They cannot form a continuous film of water over the falling oil-film though, which is the main idea behind the schematic representation of spreading phenomenon shown as Figure $5 \mathrm{~b}$. As it is illustrated in Figure 5b, a water droplet is created at the top of a falling film of mobilized oil following a thermal gradient-induced condensation process. This droplet of water cannot spread spontaneously over the oil film as the spreading coefficient of water over oil in the presence of a gas phase is negative. As a result, it tries to retain its original shape, and then would be dragged by the falling oil film towards the production spot. As time goes on, some of these separate condensed droplets would be engulfed (i.e. buried) by the continuously falling film of mobilized oil, and would form local water-in-oil (W/O) emulsion phase. Our experimental results also elucidated that there is a high level of local mixing at the proximity of the apparent SAGD interface at the pore level due to high degrees of thermal gradient, sudden thermodynamic phase change, instability of the interfaces associated with the invading phase which causes sudden jumps over their average position (i.e. Haines jumps), condensation-induced local vacuum creation, simultaneous flow of different three phases, and snap-off mechanism. This high level of local mixing could enhance the heat transfer process locally as well as convectively drain the mobilized region in a gravity-dominated process where the excessive viscous force is prohibited. It is worthwhile to note that the details of dynamic nature of these local mixing phenomena and how perfectly shaken is the near interfacial area could be studied best from motion pictures and movies recorded during the experiments.

The mobilized oil along with the enclosed water droplets establish their own drainage pathway either through the previously drained pores (which may have already been filled with condensate) under an immiscible co-current frontal advancement, or through the pores which have already drained by upward-moving steam under an immiscible counter-current frontal displacement. In either of these two cases, the degree of enclosure of water droplets within the continuum of mobilized oil could be increased. For example, if the first scenario happens, pore-level contact of draining mobilized phase with the water phase already filled the pores could cause possible drag and entrapment of water phase within the draining mobilized phase. If the draining mobilized phase tends to counter-currently flow against ascending steam phase (or enter a pore whose volume is already occupied by the steam phase), there is still the possibility of excessive heat transfer beyond the condensation limits, followed by steam condensation at the mobilized phase-steam interfacial region. This could also increase the rate of enclosure of water droplets inside the mobilized region. Water micro-droplets would be likely dispersed through the draining mobilized region to form a relatively non-homogeneous water-in-oil emulsion at the pore-level. The rate of in-situ emulsification and size of entrapped water droplets within the mobilized region could be a function of different operational and in-situ factors such as degree of superheating of the injected steam, original temperature of initial bitumen in place, operating pressure which is a function of operating temperature (either superheating or saturated states), presence of connate water saturation, injected steam quality, and convective nature of the drainage process near the well-shaken mobilized region. 


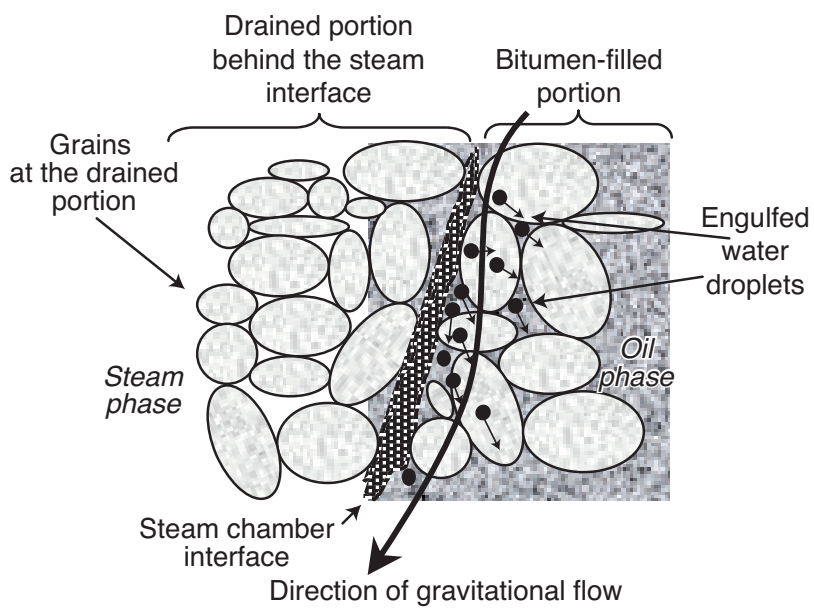

a)

Figure 5 and, b) engulfing phenomenon at the pore-scale.

Of particular interest could be the in-situ rheological behaviour of emulsion through known-structure synthetic porous media, as it is evident that the rheological and dynamic properties of emulsion would be different from those of water and mobilized oil, so does their associated viscosity magnitudes.

\section{EXPERIMENTAL SET UP AND MODEL PREPARATION FOR SAGD VISUALIZATION EXPERIMENTS}

Glass micromodels type of porous media with known pore structure was employed to conduct SAGD visualization experiments. The etched porous patterns were fully characterized in terms of physical dimensional properties as well as detailed porous pattern characteristics. This detailed characterization will be used for further quantitative porescale analysis which is out of this paper's content. Table 1 contains a summary of the micromodels characteristics in terms of the model dimensions as well as the porous pattern properties. Detailed characteristics of some of these models as well as the characterization methods have been presented elsewhere [33]. As the primary objective of this paper was to mechanistically study the SAGD process at the pore-level, only the qualitative type of analysis is provided in this article. A close-up of one of the employed glass micromodels is presented in Figure 6a. Line-source scheme of injection and production was designed for the micromodels in order to facilitate the early development of the steam chamber. As a result, the experiments cover the lateral encroachment period of the steam chamber propagation. Thanks to the symmetry

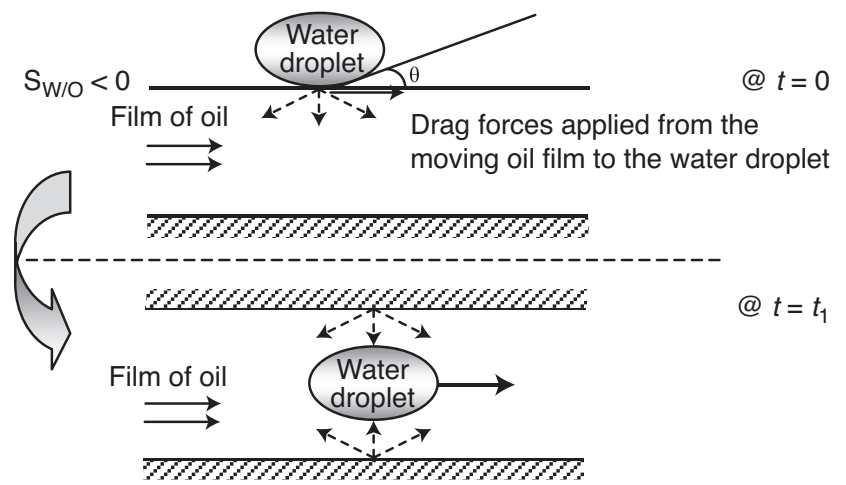

b) of the geometrical pattern of a typical SAGD process, a high permeable trough was designed at one side of the etched pattern to experimentally simulate only half of the process scheme. This ditch-like channel, which is relatively large in size (and hence permeability) comparing to the pores, was made along the entire height of the model adjacent to the pore network, to simulate a vertical line source of steam injection (i.e. left side of the micromodel in Figure 6a which is covered entirely by strips of aluminum foil). Production hole was drilled at the bottom part of the trough in order to facilitate the gravity drainage process, providing sufficient drainage height above it. Each micromodel was fitted inside a model holder and then was placed vertically to enforce the gravity-dominated flow scheme. Each micromodel was first saturated with bitumen thoroughly at elevated temperature of

\section{TABLE 1}

Physical and pore-scale characteristics of micromodels

\begin{tabular}{l|c|c|c|c}
\hline Model name & DC1 & DL1 & OM1 & OM2 \\
\hline Physical dimensions & & & & \\
\hline Length (mm) & 304 & 304 & 335.5 & 335.5 \\
Pattern length (\# of pores) & 190 & 149 & 150 & 150 \\
Width (mm) & 141 & 100 & 104.6 & 104.6 \\
Pattern width (\# of pores) & 89 & 49 & 50 & 50 \\
\hline Pore-scale dimensions & & & & \\
\hline Depth of etching ( $\mu \mathrm{m})$ & 128.1 & 249.8 & 99.2 & 181.7 \\
Pore body width (mm) & 1.31 & 2.04 & 1.65 & 1.65 \\
Pore throat width (mm) & 0.49 & 0.67 & 0.3 & 0.3 \\
Particle size (mm) & 1.11 & 0.99 & 1.2 & 1.2 \\
\hline
\end{tabular}




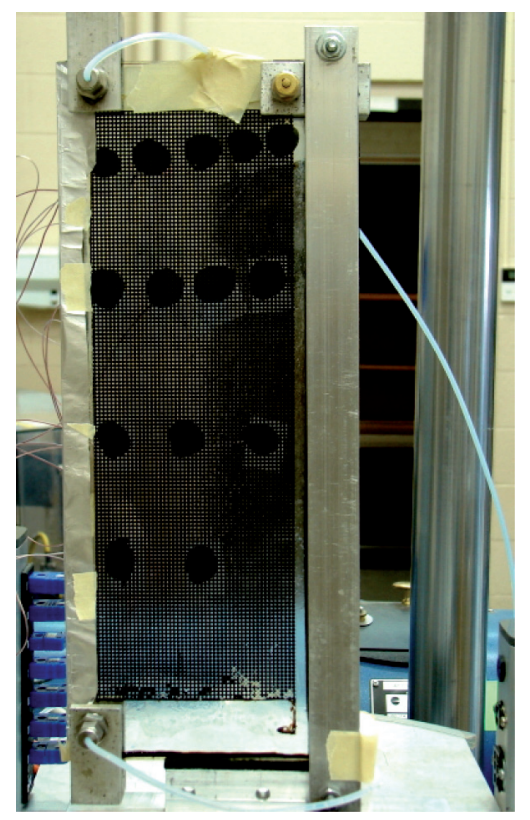

a)

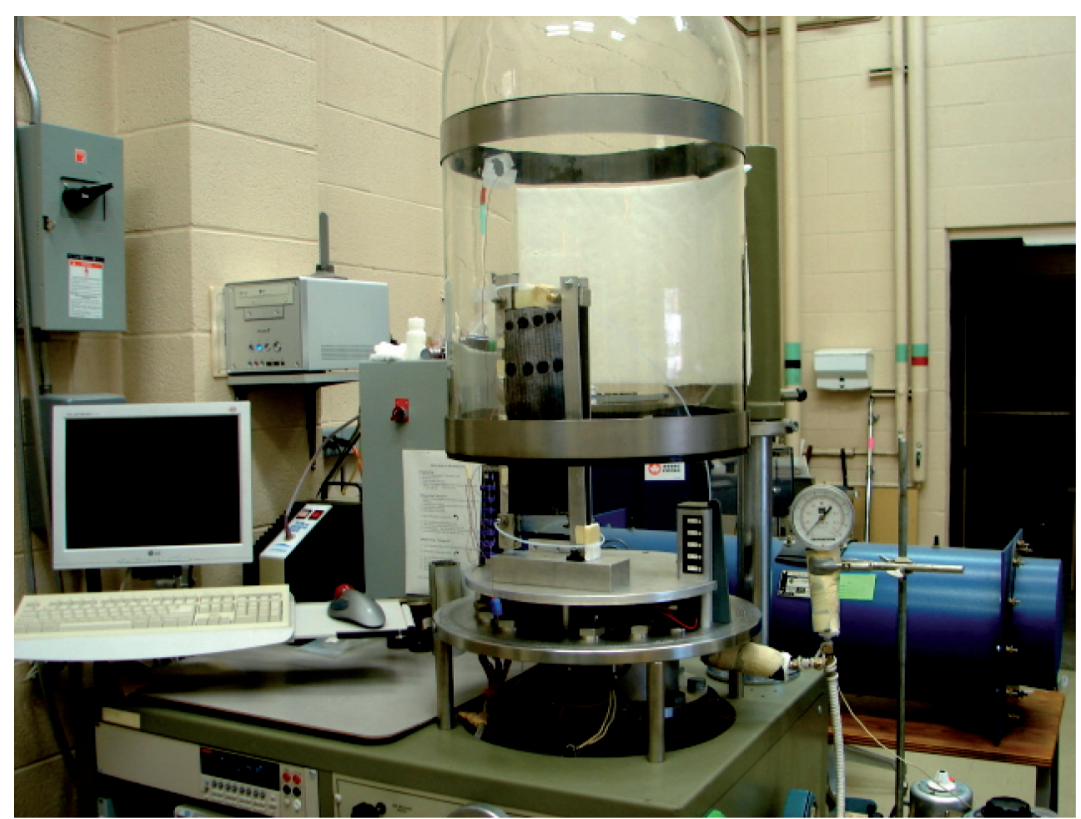

b)

Figure 6

a) A close-up of glass micromodel saturated with bitumen just before the SAGD visualization experiment, and, b) a snap shot of the employed vacuum test rig.

an oven $\left(60^{\circ} \mathrm{C}\right)$ and under a backup pressure (i.e. high pressure air line over the warm bitumen supply or using a syringe pump). The bitumen-filled micromodel was then brought into the lab environment to represent the initial experimental conditions.

A closed loop steam generation and injection system was used to play the role of steam supply facilities. All the connecting flow lines were heated/insulated to provide steam at superheated condition and also to avoid steam condensation within the transfer lines. The micromodel was then connected to the steam supply flow line at the top (i.e. injection spot). Steam was allowed to enter the micromodel at the top, and fill the trough all the way down on one side of the pore network. In order to mobilize the oil within the pores adjacent to the trough, it was needed to apply a start-up process, i.e. injection of steam through the injection line and producing it directly from the production spot. This procedure involved injecting fresh steam phase to the pores attached to the injection groove; hence initialized the mobilization process of the viscous oil. The production metering valve was then remained close in order to avoid any steam breakthrough from the production port. In other words, a finite head of drained liquids (i.e. steam condensate at the beginning and drained emulsions afterwards) was maintained continuously inside the production line to prevent steam channeling. This column of liquid was drained occasionally using the production metering valve in order to let the system to uptake as much steam as it requires for the ongoing gravity-dominated process. Visualization experiments of the SAGD process at the lab conditions suffer from the excessive heat loss from the model (which is almost at the steam temperature) to the surrounding environment (i.e. at lab temperature). As a result of this heat loss, a considerable fraction of the injected steam, which is supposed to be condensed on the cold face of bitumen, would then be condensed to make up for the above-mentioned temperature difference.

To facilitate an effective steam heating of the bitumensaturated micromodel in the absence of an undesired heat loss, a vacuum test rig capable of providing up to $10^{-6}$ torr of vacuum pressure was used as an environmental chamber. The vacuum chamber operates with a combination of a mechanical and a diffusion pump. Figure $6 \mathrm{~b}$ provides a snap shot of the employed vacuum test rig. All the visualization tests were carried out at the vacuumed environment within the air pressure range of $10^{-2}$ to $10^{-5}$ torr. It is believed that at this low value of air pressure, the amount of heat loss from the glass surface into the surrounding medium through the convection mechanism would be negligible. The only heat loss mechanism that might be of great importance at these low magnitudes of vacuum pressure is the radiation one which could be lowered by covering the hot spots of the micromodel with shiny reflective thin films such as strips of aluminum foil. It could also be lowered further by covering the portions of the inverted bell jar (that might not be needed 


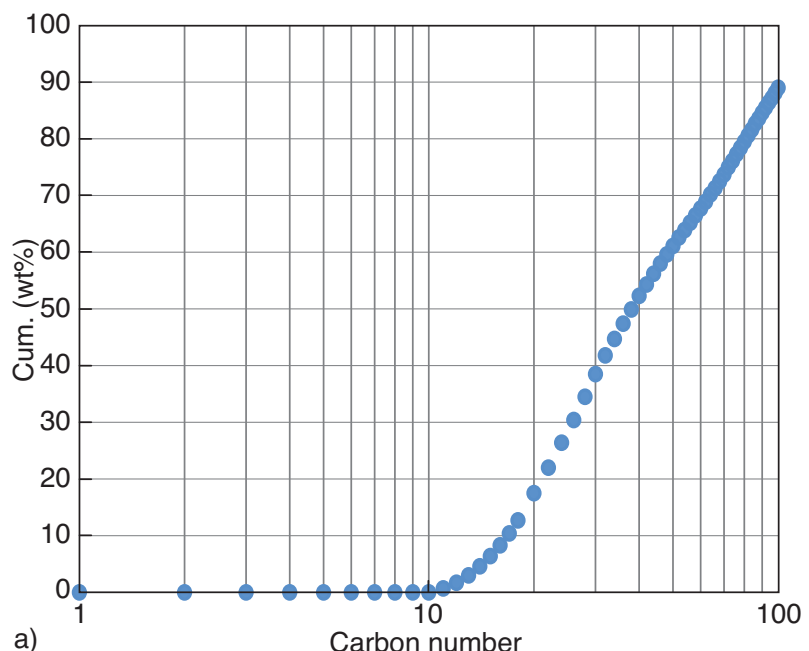

a)

Carbon number

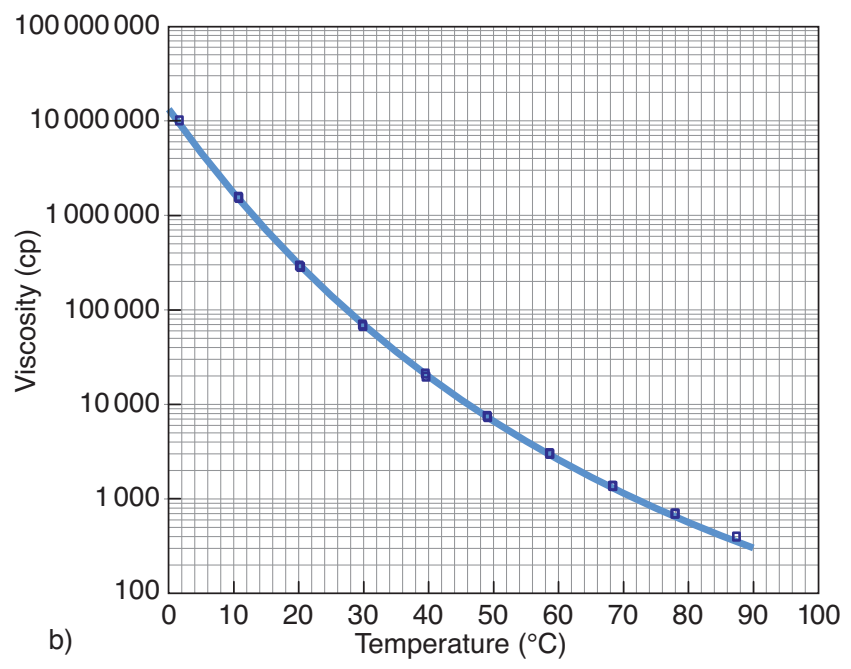

Figure 7

a) Compositional characteristics, and, b) viscosity-temperature relationship of employed Cold Lake bitumen.

from the visibility point of view) with the same shiny layers. Operating the SAGD experiments at low values of environmental air pressure prevents the steam phase to not only be condensed as a result of excessive undesired heat loss, but also allows it to transfer its latent heat of condensation only to the cold bitumen face where it is supposed to do so.

As the main purpose of this paper is to mechanistically investigate the pore-scale aspects of the SAGD process, detailed quantitative analysis of the performed experiments have not been presented. It is evident that the quantitative results obtained using 2D micromodel type of porous media cannot be extended to the real case 3D porous structure whose pores are more interconnected with higher statistical coordination number. The extent of film flow as well as the pore connectedness is higher in $3 \mathrm{D}$ porous media skeleton compared to 2D framework. However, parametric sensitivity analysis could be performed considering the effect of porous media properties, fluid properties, and operational conditions (i.e. injection flow rate, operating temperature and pressure, etc.) on the measurable experimental results which is out of the context of this paper. Figure 7 presents the compositional characteristics of the oil components and the viscosity-temperature relationship of the employed Cold Lake bitumen samples. It is worthwhile to note that the normalized weight percent of the Hectane plus component (i.e. $C_{100}^{+}$) and also heavy metals as well as nonhydrocarbon components are 10.4 and $0.6 \mathrm{wt} \%$ respectively. Each micromodel was $100 \%$ saturated with the oil phase prior to the SAGD experiment. According to the viscosity value of bitumen at $30^{\circ} \mathrm{C}$ (i.e. $70000 \mathrm{cp}$ ) and the exponential decline of viscosity versus temperature as depicted in Figure $7 \mathrm{~b}$, it is evident that the mobilized oil viscosity would be around that of water at about $130^{\circ} \mathrm{C}$.
Although recording the pore-scale phenomena was started as soon as the steam phase was injected into the micromodel, it took awhile for each particular experiment to pass the transient phase of the displacement process at which huge amounts of injected steam was just consumed (and hence condensed) in order to warm up the porous structure and create an early communication between injection and production ports. Fresh steam was injected at atmospheric pressure (to avoid any viscous-dominated oil drainage) and temperature range from corresponding saturated temperature of $100^{\circ} \mathrm{C}$ to superheated temperature of $120^{\circ} \mathrm{C}$, depending on operational conditions and injection rates of each particular SAGD trial. The observed pore-scale phenomena of the SAGD process during the flow visualization experiments were recorded in the video format as well as on photographs taken at various stages of the process to document the microscopic events of this recovery technique. Pore-level phenomena on close-up view were captured using a Canon video camera with appropriate combinations of three close-up focusing lenses (numbers 2, 3, and 4). This made it possible to have a particular focused region in view, containing a few pores as could be seen in figures presented in this paper.

\section{EXPERIMENTAL RESULTS AND DISCUSSION}

Pore scale flow visualizations of SAGD process reveal several mechanisms happening in the vicinity of the apparent bitumen-steam interface. In this section, a series of pore-scale visualization events is reported and relevant mechanistic study of these events is also provided. 


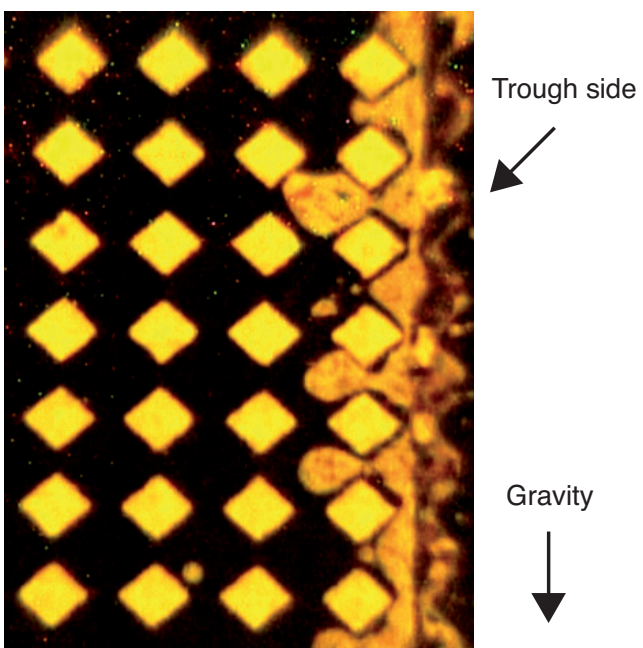

Figure 8

Lateral development of steam chamber initialization by early steam invasion from trough to the adjacent pores.

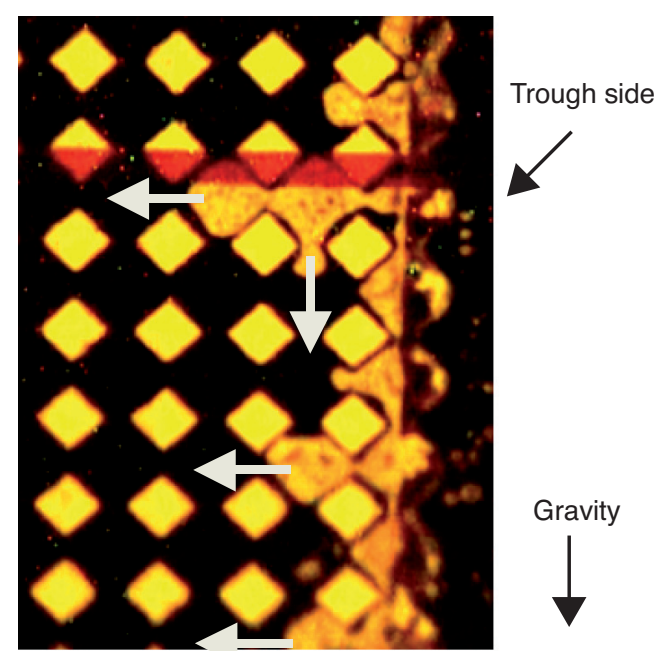

Figure 9

The same location as Figure 8, but at a later time frame (i.e. 3 minutes later).

\subsection{Pore-Scale Events Analysis: Steam Chamber Early Development and its Lateral Encroachment}

As it was stated before, presence of high permeable trough extended at one side of the micromodel not only eases the saturation stage of the micromodel, but also provides an early communication between injection and production spots. During the early lateral development of the steam chamber, bitumen present in the pores which are adjacent to the high permeable trough achieves mobility as soon as steam introduces to the model. Local invasion of steam into these vulnerable pores is the first sign of steam chamber lateral development at the pore scale. This phenomenon which is supported by the thermal diffusion driving force could be seen in two successive pictures demonstrated as Figures 8 and 9. Mobilized oil is drained out of these pores and steam invades through them following the sequential behaviour of pore drainage during an immiscible displacement process [32].

During the early stages of steam chamber lateral displacement, the chamber could be defined by the continuum of gas invaded pores which is dendritic in nature. These pores are well interconnected from the steam flow point of view; however, there is the possibility of steam condensation at the tip of each contact point of steam-invaded pores with bitumenfilled pores. This local condensation could happen either through a pore constriction, or within the entire pore body. Figure 10 shows the early development of the steam chamber and different flow zones in the vicinity of the apparent interface. The pores adjacent to the nominal interface drain preferentially in the direction of gravity, and form dead- end type of structure. As a result, the drainage of the oil films could then be re-directed, which could lead potentially to creation of peaks-and-valleys configuration of flow pathways at the nominal interface such as those pointed out with red arrows. Presence of peaks-and-valleys type of interfacial pattern could be avoided if continuous films of mobilized oil exist at the pore scale, flow down gradient just ahead the nominal interface, and fill the localized valleys to the extent of creating a relatively smooth apparent interface extended vertically under the action of gravity. This is discussed further in details later when different drainage displacement mechanisms at the pore level are explained. These localized peaks and valleys are formed at the uneven nominal SAGD interface (i.e. red dotted curve) just behind a relatively thick layer of pores so called "mobilized region".

\subsection{Pore-Scale Events Analysis within the Mobilized Region}

The mobilized region contains thermally-mobilized oil, droplets of condensate, and also steam phase which are flowing simultaneously parallel to the apparent interface. In this region (whose varying thickness at different particular elevations is shown by dotted purple arrows in Figure 10, which is in the order of 1-6 pores ahead of the nominal SAGD interface), most of the convective nature of the SAGD process in the vicinity of the apparent interface as well as severe local mixing at the pore-scale could be observed. Different acting forces are contributing to the simultaneous fluid flow within this region, namely gravity, capillarity, and buoyancy forces in the absence of excessive viscous force. 


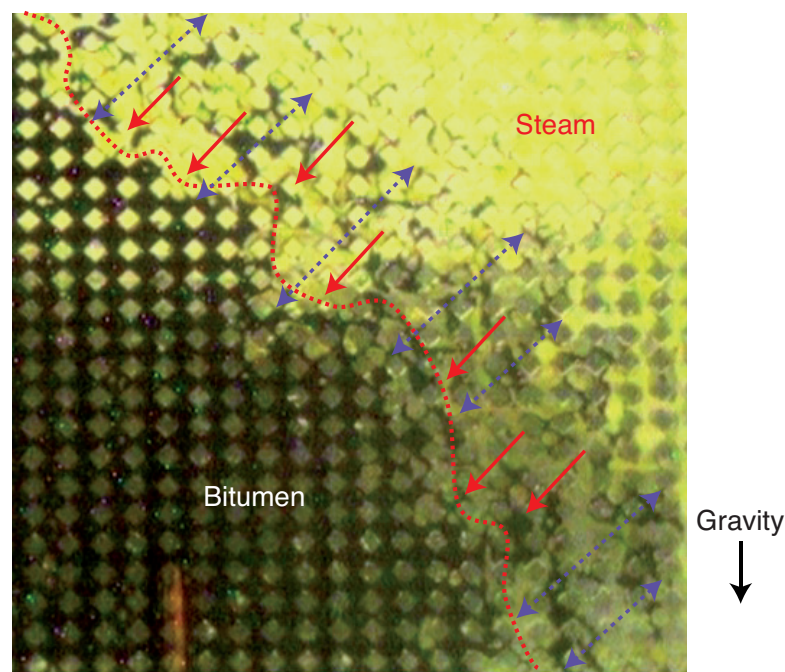

Figure 10

Visualization of the skeleton of apparent SAGD interface, steam flow pathways, and mobilized region.

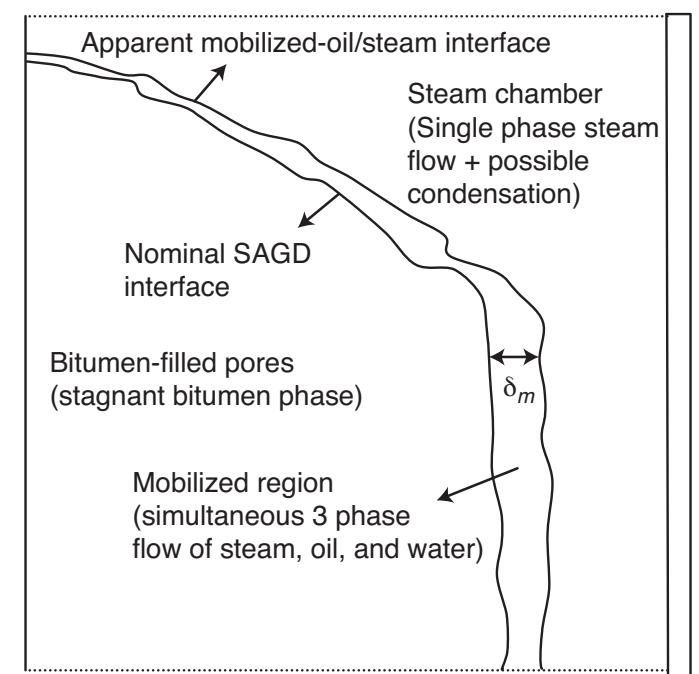

Figure 11

Schematic pore-level diagram of fluid flow zones in a typical SAGD process according to flow visualization results.
This region is formed due to the presence of effective thermal diffusion at the pore scale, and it clearly has an oriented structure, in which three different fluid phases are flowing parallel to the nominal SAGD interface (i.e. apparent distinction of steam and oil phases at the macroscopic level). Unlike the limited drainage depth of the live oil in the VAPEX process, which is in the order of 1-2 pores as a result of slow molecular diffusion [33,34], our visualization results revealed that depth of SAGD mobilized region (i.e. " $\delta_{\mathrm{m}}$ " in Fig. 11) is 2-3 times thicker compared to that of the VAPEX process. This is due to the considerably higher magnitudes of the thermal diffusion, which is a measure of the extent of the heat transfer process, compared to those of the molecular diffusion, which is responsible for the local mass transfer process. This point could also be verified knowing the fact that even the oil within the pores away (i.e. 1-5 pore body dimensions) from the nominal interface is also being mobilized as a result of localized thermal diffusion. This point would be backed up with gravitational drainage of the enclosed droplets of water within the continuum of oil right behind the nominal interface in later sections when the porescale emulsification aspects is being discussed.

Transport mechanisms involved in a typical SAGD process include heat transfer by thermal diffusion, and convective mixing (i.e. convection) of the steam and condensate phases with the heavy oil, as well as the gravity drainage of the viscosity-reduced oil along with the steam condensate. The mobilized oil as well as the steam condensate within the mobilized region would be drained by the action of gravity when gravity force overcomes the capillary and possible viscous forces. The predominant factor is the reduction of viscous drag due to the exponential reduction in inherent viscosity upon steam heating. The role of gravity (i.e. density difference) and capillary forces (i.e. capillary pressure) depends on the individual pore scale mechanisms. According to our flow visualization experiments, there are different pore-level fluid flow zones in a typical SAGD process which are schematically presented in Figure 11. These zones can be characterized as follows:

- Steam chamber in which steam is the predominant flowing phase. However, there is the possibility of steam condensation followed by condensate movement if its saturation provides enough relative permeability value;

- Bitumen-filled pores: This zone is the stagnant zone in which in-situ bitumen viscosity is still beyond the mobilization limit. Heat would be transferred to this zone by a combination of conduction and convection mechanisms;

- Mobilized region in which simultaneous three phase flow of mobile oil, steam, and water could be observed.

Nominal SAGD interface is a hypothetical distinction line (or surface when 3D skeleton structure is concerned) separating bitumen-filled pores from the mobilized region. Apparent mobilized oil-steam interface is the other hypothetical $1 \mathrm{D}$ or $2 \mathrm{D}$ boundary of the mobilized region, ahead of the nominal SAGD interface. Figures 12 and 13 present closer looks at the pore-level view of the mobilized region. Figure 12 shows the direct contact of steam and oil just at the nominal SAGD interface, i.e. all the pore bodies below this particular location contain only oil phase. Red arrow shows the vertically-oriented film flow drainage of the mobilized oil in the presence of the steam phase. One can clearly note the distribution of all three flowing phases within 


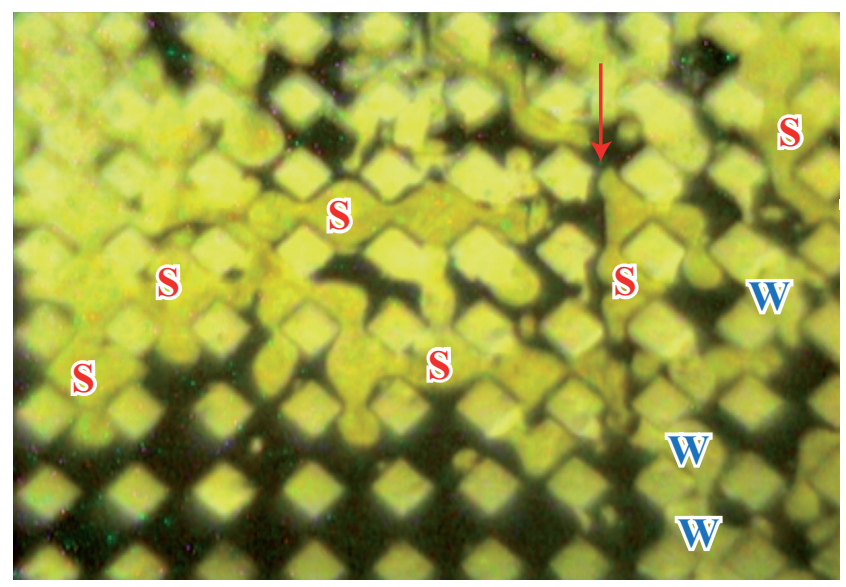

Figure 12

A closer look at the pore-level mobilized region.

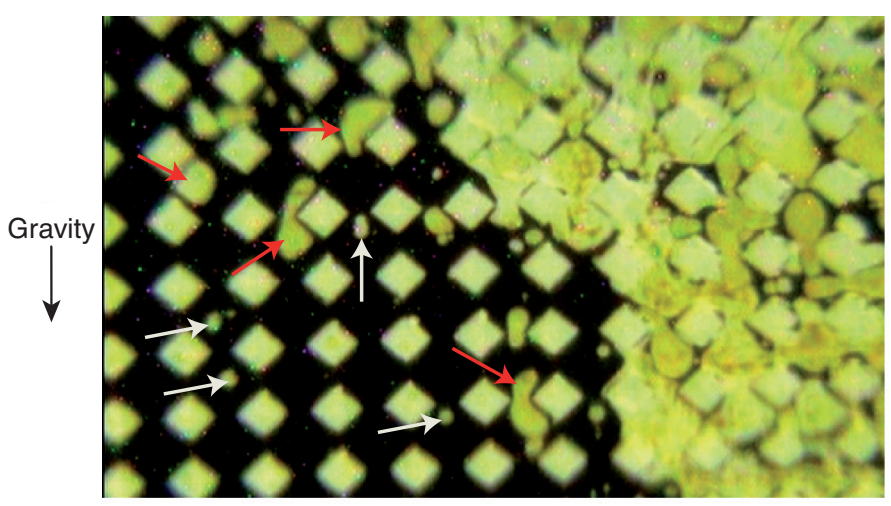

Figure 13

Oil phase mobility behind the apparent SAGD interface. this pore-scale snap shot. Figure 13 shows the mobilized region (to the right), apparent SAGD interface, and oilsaturated pore bodies (to the left) behind the nominal interface. It is clear that some small bubbles of the steam phase are trapped within the draining live oil (behind the interface to the left), which are pointed out by thin red arrows. In addition, enclosure of small droplets of water is also evident within the continuum of mobile oil just behind the nominal interface (thick white arrows). Continuous drainage of these trapped bubbles and droplets is an evidence to the fact that oil phase behind the nominal SAGD interface (within a limited distance in the order of 1-5 pore body dimensions) is mobile enough to be drained gravitationally.

One could clearly observe the state of microscopic fluids distributions within the mobilized region with a quick look at Figure 14. As it is evident in all of these snapshots, steam phase (i.e. " $S$ ") invades through the core part of the pores as the only truly non-wetting phase, and interacting liquids attach to the grain solids (i.e. " $G$ ") whenever applicable as the wetting phases. Spreading characteristics of oil over water (i.e. " $W$ ") at the pore scale is evident. In addition, it seems that liquid films (either oil or water) tend to keep their capillary continuity along two adjacent grain particles. Areas within dotted ellipses show the local engulfment of tiny water droplets inside the oil phase.

\subsection{Pore-Scale Drainage Mechanisms}

According to flow visualization results, two pertaining drainage mechanisms are responsible for pore-scale sweeping efficiency of a typical SAGD process, namely as 1) capillary drainage displacement mechanism, and 2) film-flow type of drainage mechanism. These two simultaneous mechanisms are acting within the mobilized region and also through a few pores just behind the apparent SAGD interface, displacing the already mobilized oil with the aid of gravitational force.

\subsubsection{Capillary Drainage Displacement Mechanism}

Under this displacement mechanism, a finite volume of mobilized oil, which can be considered as a continuum compared to the slim films of oil within the mobilized region, would be drained both within and behind (i.e. limited distance of 1-5 pores) the mobilized region by direct drainage displacement applied by the invading steam phase according to the typical sequential drainage displacement of a wetting phase using a non-wetting phase at the pore scale [32]. Meanwhile, this direct drainage displacement would be facilitated with the aid of gravitational force in the absence of excessive viscous forces. It was previously noted that there is a severe local mixing within the mobilized region during the course of a typical SAGD process. This induced local mixing could enhance the convective element of the overall drainage displacement at the pore scale. This type of displacement is pointed out by white arrows in Figure 9. In addition, Figure 15 provides a series of pore-scale events including sequential drainage displacement of wetting (oil) phase by non-wetting (steam) phase over a 6-minutes time period. As the oil in contact with steam phase is heated to the extent of being readily mobilized, it is convenient to observe drainage of several pores in a serial format at the same time. As it is depicted in this figure, steam is displacing oil downwards along the yellow arrows shown in one of the snap shots (i.e. " $b ")$ and they are drained almost simultaneously under the action of gravity. The same process could also be observed in Figure 16 which shows the capillary drainage displacement phenomenon (along the face-down red arrows) just behind the mobilized region (i.e. red dotted rectangular area). It is clear that all three interacting phases are flowing 

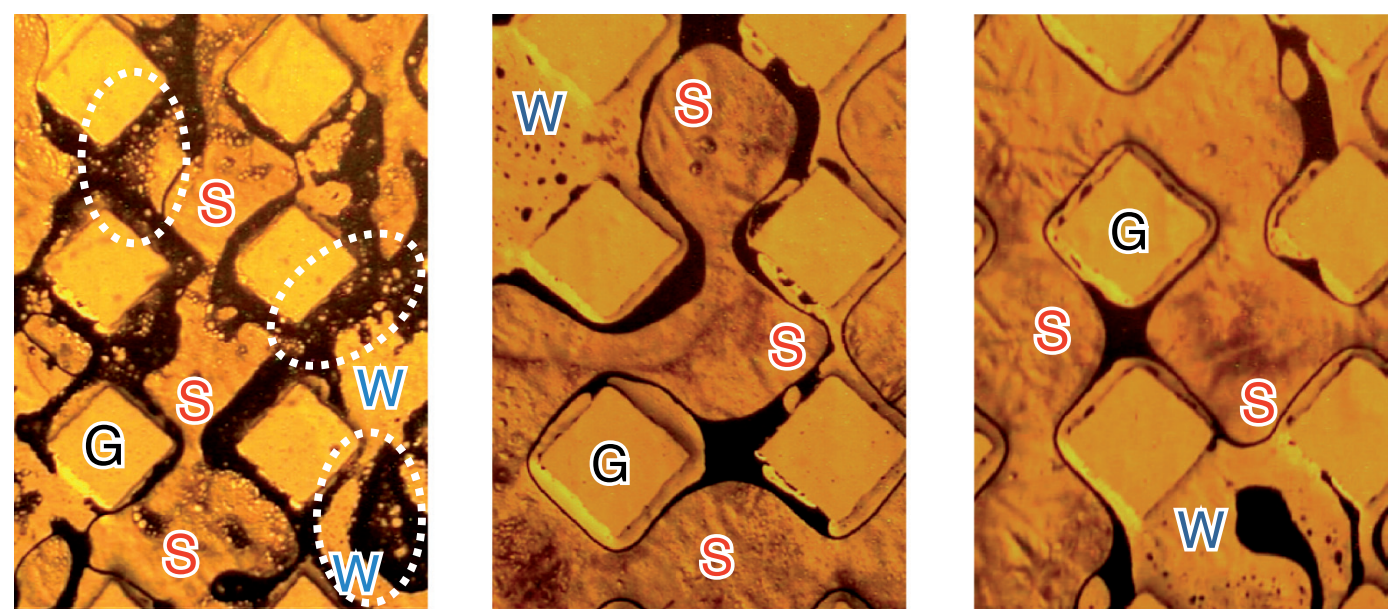

Figure 14

State of fluids distributions within the mobilized region at the microscopic scale.

simultaneously within the tiny portion of the mobilized region which is shown in this figure (condensate: light blue arrows, steam: white arrows, and draining oil: verticallyextended white ellipse).

\subsubsection{Film-Flow Drainage Displacement Mechanism}

This type of drainage displacement mechanism is also involved as an effective pore-scale displacing mechanism especially within the mobilized region as well as inside the steam-saturated zone. The oil films left behind in the steam invaded region periodically form loop structures involving tiny films in steam invaded pores. If these films keep their inherent flow continuity over the limited distance of their extension, there is the possibility of their drainage under film flow drainage displacement. The drainage rate of these closed-loop oil films is lower than that of the bulk oil within the pores which are swept away under the combinatory effects of viscosity loss as well as direct drainage displacement. This is because of the reduced hydraulic conductivity of thin oil films within the steam invaded pores. The high degree of local mixing associated with the mobilized region usually does not allow sufficient extended flow continuity for the draining oil films, resulting in poor contribution of filmflow drainage component in overall drainage scheme of the mobilized region. Figure 15 also shows limited degrees of film-flow type of drainage in which thin films of oil left behind within the steam invaded pores (top portions of all the snap shots which are indicated by horizontal white dotted ellipses in Fig. 15a,b) are draining under the film-flow type of displacement over the internal surface of the pore bodies in presence of non-wetting phase. As time proceeds, one can observe the periodic thickening and thinning of the oil wedge thickness just besides the leading edge of the invading steam (i.e. white dotted vertically-extended ellipses in Fig. 15b-d), approving the presence of film-flow drainage mechanism at that localized spot up until the last snap shot at which there are less signs of closed-loop draining films all over the top portion of the scheme compared to the earlier timeframes.

\subsection{Emulsion Creation at the Pore-Scale}

Our flow visualization experiments support the hypothesis provided previously regarding pore-scale emulsification during the course of conventional SAGD process. Invading steam phase could be condensed locally as a result of local heat transfer either within the mobilized region (ahead of the nominal SAGD interface and behind the steam-mobilized oil interface) or at the nominal SAGD interface (i.e. apparent interface between bitumen phase and mobilized oil region). In other words, liquid condensate could be seen either within the mobilized region or at the nominal SAGD interface. According to the non-spreading characteristics of water over oil in presence of a gas phase, local enclosure of water blobs within the continuum of oil behind the nominal interface would result in localized water in oil emulsification. Figure 17 shows three snapshots regarding state of the in-situ emulsification in the SAGD process. Figure 17a shows the local entrapment of a large number of water micro-droplets within the continuum of oil at the pore scale. The selected area is one pore-body-dimension distant from the nominal interface. Figure 17b presents the engulfment of two individual water droplets inside the pool of oil with a distance equivalent to three-pore-dimensions from the nominal SAGD interface. Figure $17 \mathrm{c}$ also demonstrates the microscopic enclosure process of a number of small condensate droplets (left side of the picture) which were 


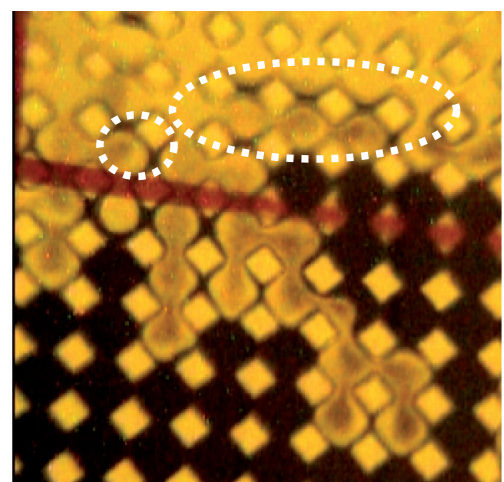

a)

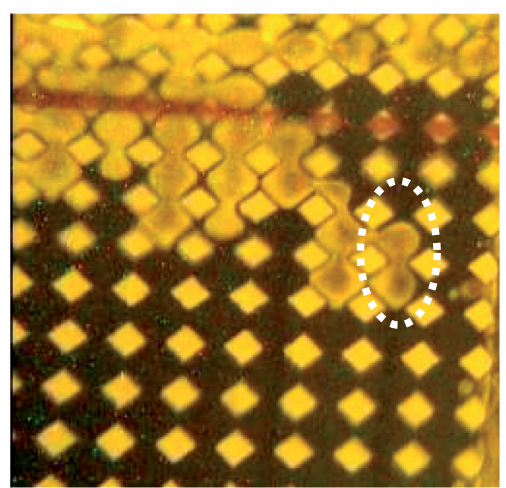

d)

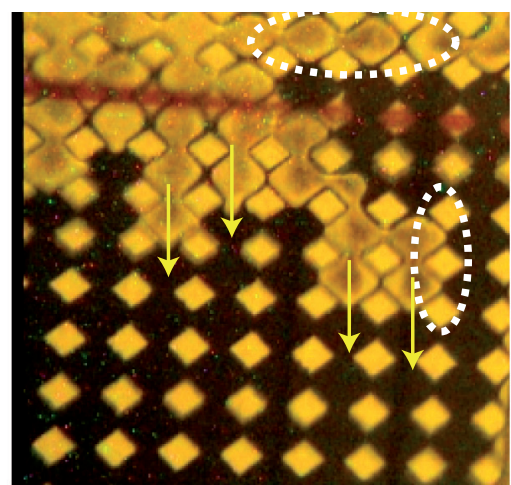

b)

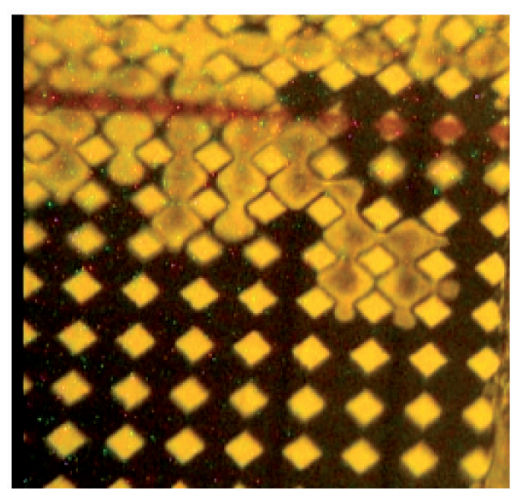

e)

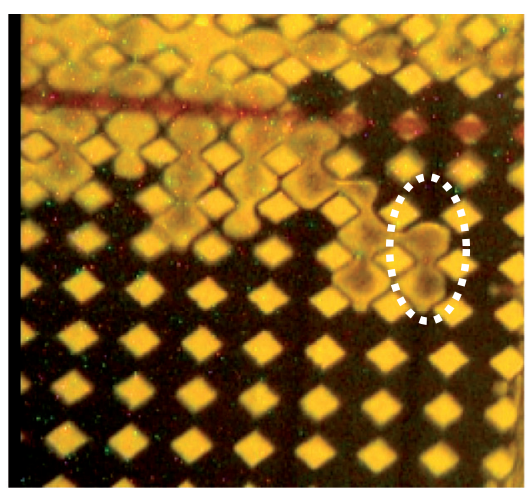

c)

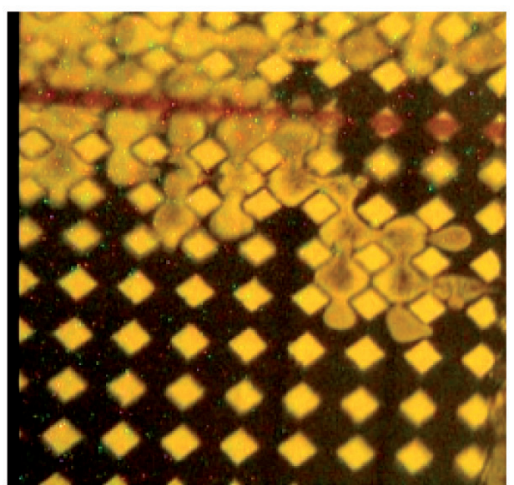

f)

Figure 15

Sequence of pore drainage under capillary drainage displacement of wetting phase (oil) by invading non-wetting phase (steam) as well as film-flow type of drainage displacement at the pore scale.

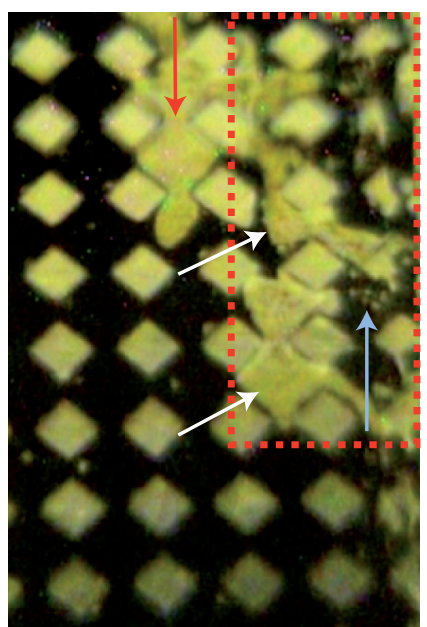

a)

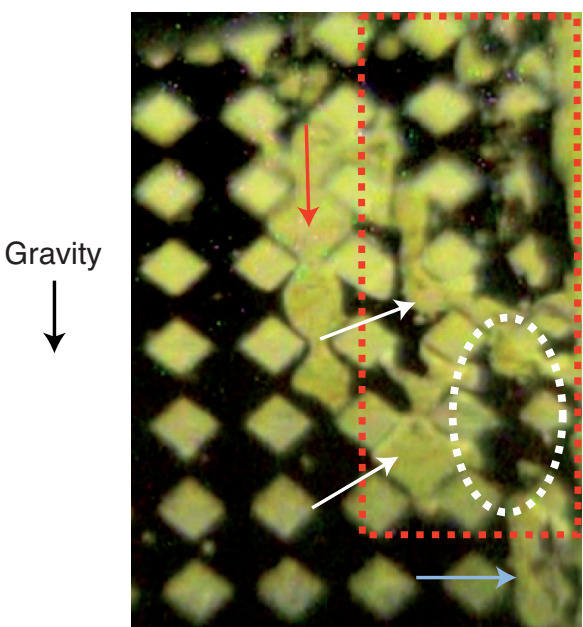

b)

Figure 16

Capillary drainage displacement of wetting phase (oil) by invading non-wetting phase (steam) at the pore scale. 


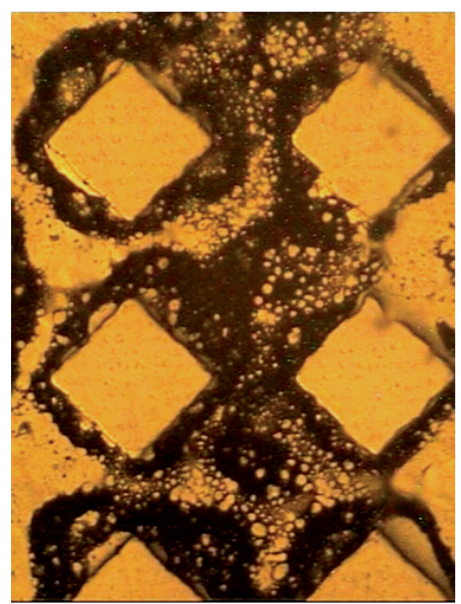

a)

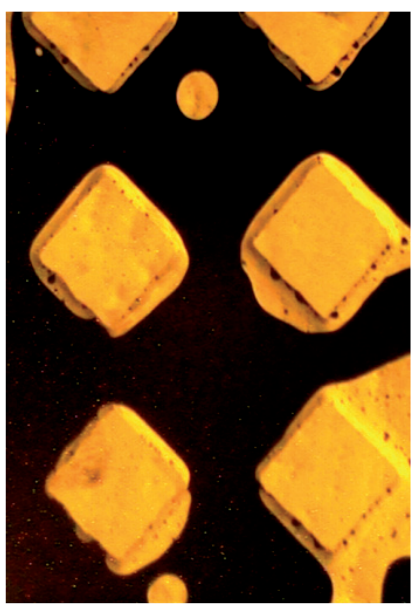

b)

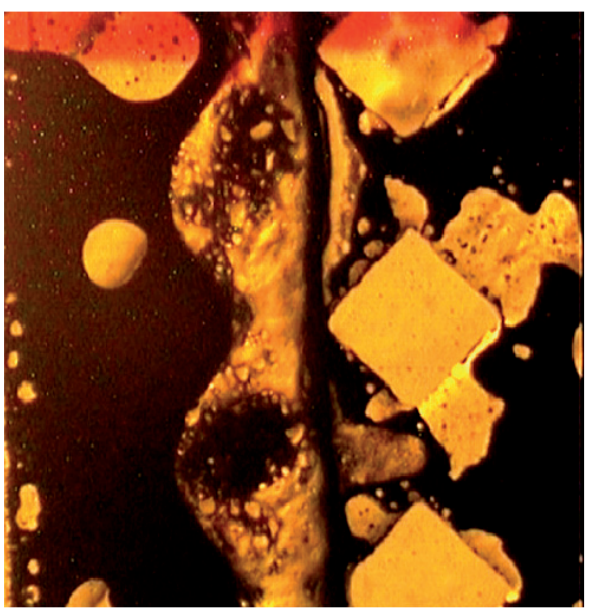

c)

Figure 17

State of the in-situ emulsification during the SAGD process at the pore scale obtained from flow visualization experiments.

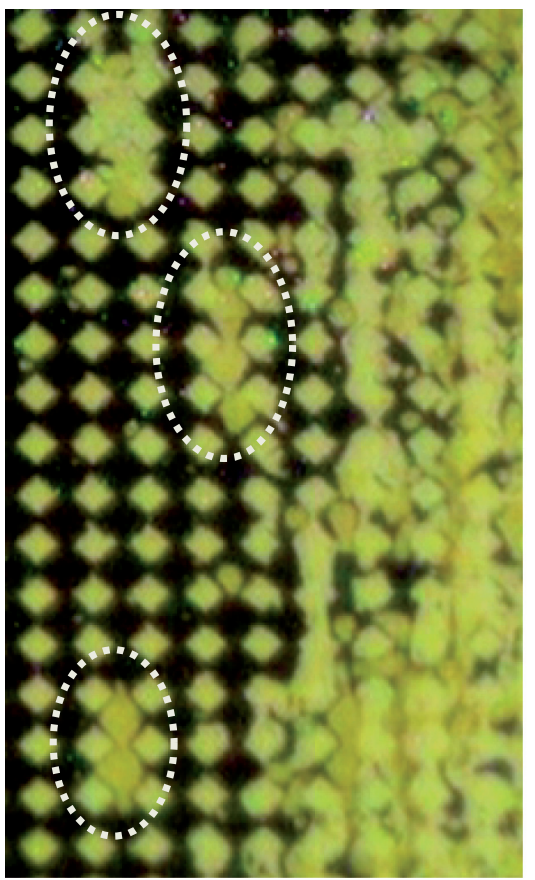

a)

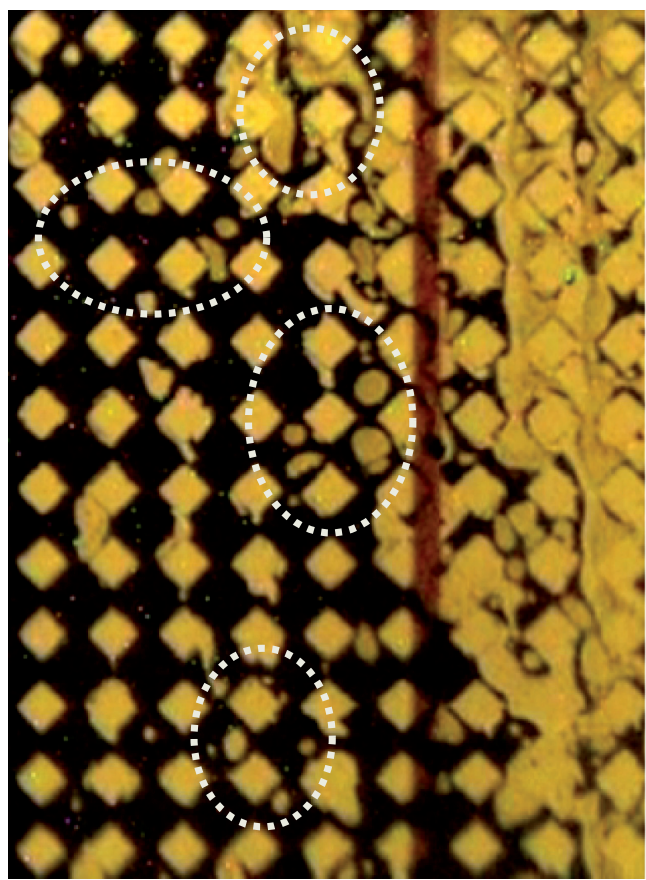

b)

Figure 18

Entrapment of small steam bubbles as well as condensate droplets behind the nominal SAGD interface within the mobilized draining oil.

detached from the bulk column of condensate formed at the top of the oil-filled pores.

Depth of enclosure (i.e. engulfment) of tiny condensate droplets could reach up to 5 pores behind the nominal SAGD interface. The trapped droplets of condensate could then be dragged by the surrounding continuum of mobilized oil down gradient. They may be joined together if their enclosure density is high enough, i.e. large number of engulfed condensate droplets would be trapped by the reducedviscosity oil continuum. In addition, they should overcome the associated film pressure of the tiny mobilized oil films in between in order to be able to coalesce to each other. Due to 
the convective nature of the drainage process within the mobilized region, it was observed that both the condensate droplets and also small steam bubbles have the capability to be trapped within the mobilized continuum of oil just behind the apparent interface. Snap off mechanism of the invading immiscible front could also facilitate this trapping process. Figures 13 and 18 (both right and left pictures) present three sample snapshots in which the entrapment of small condensate droplets as well as finite-pores-extended steam bubbles are demonstrated.

\section{CONCLUSIONS}

A series of flow visualization experiments were conducted using glass micromodels to mechanistically investigate the pore-scale aspects of the SAGD process. This visualization study indicates that:

- periodic condensation of steam at the nominal SAGD interface causes condensate build up ahead of the apparent interface which is an indicative of the local heat transfer mechanism of the process at the pore-level. Direct drainage displacement of this condensate by invading steam phase enhances local pore-scale mixing within the mobilized region ahead of the nominal SAGD interface. Moreover, mobilized-oil filled pores are cleaned up by a combinatory effect of direct drainage displacement of oil by condensate as well as by steam, and film-flow drainage displacement;

- simultaneous three phase flow of steam, condensate, and mobilized oil was observed within the mobilized region, ahead of the apparent SAGD interface. Steam could be considered as the only truly non-wetting phase during this gravity drainage process. A series of simultaneous cocurrent and counter-current flow of phases is responsible for lateral encroachment of the steam-saturated zone;

- periodic rupture of the oil films results in complete oil mobilization with very limited residual phase within the steam invaded zone;

- small steam pockets, which remain in contact with the mobilized-oil filled pores for long periods of time, enhance the local heat transfer process ahead of the apparent interface, followed by local steam condensation. The engulfment process of condensate droplets within the continuum of mobilized oil is responsible for the local water in oil emulsification at the pore level.

\section{ACKNOWLEDGMENTS}

The financial support of this research provided by the Natural Sciences and Engineering Research Council of Canada (NSERC) is gratefully acknowledged. The authors would like to express their gratitude to the Micro-Electronics and
Heat Transfer Laboratory (MHTL) - University of Waterloo, especially Professor Richard Culham (MHTL director) and Professor Pete Teertstra, for providing continuous support during the course of visualization studies.

\section{REFERENCES}

1 National Energy Board of Canada (2006) Canada's oil sands: opportunities and challenges to 2015, an update, June.

2 Butler R.M., McNab G.S., Lo H.Y. (1979) Theoretical studies on the gravity drainage of heavy oil during in-situ steam heating, 29th Canadian Chemical Engineering Conference, Sarnia, Ontario, October 1-3.

3 Butler R.M., McNab G.S., Lo H.Y. (1981) Theoretical studies on the gravity drainage of heavy oil during steam heating, Can . J. Chem. Eng. 59, 455-460.

4 Butler R.M. (1991) Thermal Recovery of Oil and Bitumen, Prentice Hall Inc., New Jersey.

5 Butler R.M. (1994) Horizontal wells for the recovery of oil, gas and bitumen, Petroleum Society Monograph Number 2, Canadian Institute of Mining Metallurgy and Petroleum.

6 Butler R.M. (1994) Steam-assisted gravity drainage: concept, development, performance, and future, J. Can. Petrol. Technol. 32, 2 .

7 Butler R.M. (1998) SAGD comes of age, J. Can. Petrol. Technol.37, 7 .

8 Butler R.M. (2001) Some recent developments in SAGD, Distinguished JCPT Author Series 40, 1.

9 Butler R.M. (2004) The behaviour of non-condensible gas in SAGD - a rationalization, J. Can.Petrol.Technol. 43, 1 .

10 Al-Bahlani A.M., Babadagli T. (2009) SAGD laboratory experimental and numerical simulation studies: A review of current status and future issues, J. Petrol. Sci. Eng., doi:10.1016/j.petrol.2009.06.011.

11 Chatzis I., Morrow N., Lim H.T. (1983) Magnitude and detailed structure of residual oil saturation, SPE J., April, 311-326.

12 Wan J., Tokunaga T.K., Tsang C., Bodvarsson G.S. (1996) Improved glass micromodel methods for studies of flow and transport in fractured porous media, Water Resour. Res. 32, 7, 1955-1964.

13 Feng Q., Di L., Tang G., Chen Z., Wang X., Zou J. (2004) The mechanism of Water Alternative Gas displacement in porous media, 14th SPE-IOR Symposium, SPE paper 89362, Tulsa, OK, April, 17-21.

14 Sohrabi M., Henderson G.D., Tehrani D.H., Danesh A. (2000) Visualization of oil recovery by water alternating gas (WAG) injection using high pressure micromodels - Water-wet systems, SPE-ATCE, SPE paper 63000, Dallas, TX, Oct. 1-4.

15 Sohrabi M., Danesh A., Jamiolahmady M. (2007) Visualization of residual oil recovery by near miscible gas and SWAG injection using high-pressure micromodels, Transport Porous Med. 74, 2, 239-257.

16 Sohrabi M., Danesh A., Jamiolahmady M. (2007) Microscopic mechanisms of oil recovery by near-miscible gas injection, Transport Porous Med. 72, 3, 351-367.

17 Gates I.D., Chakrabarty N. (2005) Optimization of SteamAssisted Gravity Drainage in McMurray reservoir, 6th CIPC (56th Pet. Soc. Ann. Tech. Meet.), Paper No. 2005-193, Calgary, Canada, June. 
18 Gates I.D., Kenny J., Hernandez-Hdez I.L., Bunio G.L. (2005) Steam-injection strategy and energetics of Steam-Assisted Gravity Drainage, SPE/PS-CIM/CHOA Int. Thermal Operations and Heavy Oil Symposium, SPE paper 97742 and PS Paper 2005-332, Calgary, Canada, November.

19 Butler R.M. (1987) Rise of interfering steam chamber, J. Can. Petrol.Technol. 26, 3, 70-75.

20 Ito Y., Ipek G. (2005) Steam fingering phenomenon during SAGD process, SPE/PS-CIM/CHOA Program Committee, also SPE Int. Thermal Operations and Heavy Oil Symposium, SPE Paper 97729, Calgary, AB, Canada, November 1-3.

21 Ito Y., Hirata M., Ichikawa M. (2004) The effect of operating pressure on the growth of the steam chamber detected at the Hangingstone SAGD project, J. Can. Petrol. Technol. 43, 1, January.

22 Ito Y., Suzuki S (1996) Numerical simulation of the SAGD process in the Hangingstone oil sands reservoir, 47th Annual Technical Meeting of the Petroleum Society, Paper 96-57, Calgary, AB, Canada, June 10-12.

23 Walls E., Palmgren S., Kisman K. (2003) Residual oil saturation inside the steam chamber during SAGD, J. Can. Petrol. Technol. 42, 1, January.

24 Chung K.H., Butler R.M. (1987) Geometrical effect of steam injection on the formation of emulsions in the Steam Assisted Gravity Drainage process, 38th Pet. Soc. Ann. Tech. Meet. of CIM, Paper 87-38-22, Calgary, Canada, June.

25 Nasr T.N., Law D.H.S., Golbeck H., Korpany G. (2000) Counter-current aspect of the SAGD Process, J. Can. Petrol. Technol.39, 1, January.

26 Chung K.H., Butler R.M. (1989) In-situ emulsification by the condensation of steam in contact with bitumen, J. Can. Petrol. Technol. 28, 1, Jan.-Feb.

27 Noik C., Dalmazzone C., Goulay C., Glenat P. (2005) Characterization and emulsion behaviour of Athabaska extra heavy oil produced by SAGD, SPE paper 97748, 2005 SPE International Thermal Operations and Heavy Oil Symposium, Calgary, Alberta, Canada, Nov. 1-3.
28 Sasaki K., Akibayashi S., Yazawa N., Kaneko F. (2002) Microscopic visualization with high-resolution Optical-Fiber Scope at steam chamber interface on initial stage of SAGD process, SPE paper 75241, SPE/DOE Improved Oil Recovery Symposium, Tulsa, OK, April 13-17.

29 Sasaki K., Akibayashi S., Yazawa N., Doan Q., Farouq Ali S.M. (1999) Experimental modeling of the SAGD process Enhancing SAGD performance with periodic stimulation of the horizontal producer, SPE paper 56544, SPE Annual Technical Conference and Exhibition, Houston, TX, October 3-6.

30 Sasaki K. et al. (1996) Experimental study on initial stage of SAGD process using 2-dimensional scaled model for heavy oil recovery, SPE paper 37089, 2nd International 3-Day Conference on Horizontal Well Technology.

31 Sasaki K., Akibayashi S., Yazawa N., Doan Q.T., Farouq Ali S.M. (2001) Experimental modeling of the SAGD process enhancing SAGD performance with periodic stimulation of the horizontal producer, SPE paper 69742, SPE J., March.

32 Chatzis I., Dullien FAL (1983) Dynamic immiscible displacement mechanisms in pore doublets - theory versus experiment, J. Colloid Interf. Sci. 91, 1, 199-222.

33 James L.A. (2009) Mass transfer mechanisms during the solvent recovery of heavy oil, PhD Thesis, University of Waterloo.

34 James L.A., Rezaei N., Chatzis I. (2008) VAPEX, Warm VAPEX, and Hybrid WAPEX - The state of enhanced oil recovery for in-situ heavy oils in Canada, Technology Brief, $J$. Can. Petrol. Technol. April.

Final manuscript received in January 2010 Published online in December 2010 